February 2000

\title{
Monetary Policy Coordination: A New Empirical Approach*
}

\begin{abstract}
This paper examines the degree of monetary policy coordination between major industrialized countries from a completely new perspective. The analysis uses a new data set on central bank issued interest rate targets for 14 OECD countries. The methodology that we use decomposes the notion of coordination into two components: (1) Do countries coordinate the timing of their monetary policy actions? and (2) Is there coordination in the direction in which targets are changed? The answers to these two questions are based on a newly developed dynamic discrete duration model (the autoregressive conditional hazard model or $\mathrm{ACH}$ ) and on an ordered response model in event time. The results indicate there is significant policy coordination among these 14 countries during the 1980-1998 sample period in contrast to recent theoretical work suggesting that gains to coordination are small. Moreover, this coordination appears to work through channels other than documented coordination agreements.
\end{abstract}

- JEL Codes: F42, E58, F47

- Keywords: monetary policy, international coordination, interest rate targets.

Paul R. Bergin

and

Oscar Jorda

Dept. of Economics

U.C. Davis

One Shields Ave

Davis, CA 95616-8578

e-mail:

prbergin@ucdavis.edu

ojorda@ucdavis.edu

*Acknowledgements: This research was funded by a grant from the Institute of Governmental Affairs, U.C. Davis. The authors wish to thank Robert Feenstra, Greg Sutton, Alan Taylor and participants of the Macro/International Economics workshop at U.C. Davis for useful comments and suggestions. Selva Demiralp and Kristin van Gaasbeck provided extraordinary research assistance. 


\section{Introduction}

Coordination of national monetary policies has become a subject of renewed interest of late, largely because of recent advances in the modeling of open economies. Obstfeld and Rogoff (2000) and Benigno (2000) have begun a re-exploration of international policy coordination using models that consider the microeconomic foundations of nominal rigidities and household welfare. On one hand, these papers point out potential benefits of coordination by internalizing terms of trade externalities. However, Obstfeld and Rogoff (2000) in particular find that the welfare gains are likely to be quantitatively small in comparison to the gains from domestic stabilization policy. These conclusions roughly agree with findings of previous literature using older Keynesian models, although the reasoning behind these conclusions differs. $^{1}$

Despite the theoretical prediction that gains are small, there is a large empirical literature that has claimed to find evidence that countries do in practice coordinate their macroeconomic polices to some degree. Studies focusing on the major industrial countries generally find evidence that the U.S. acts as a leader for policy makers in certain countries, but the mechanisms through which this coordination takes place are often unclear. (See Dominguez (1997), Furman and Leahy (1996), Chung (1993), Burdekin (1989), Burdekin and Burkett (1992), and Batten and Ott (1985).) Another branch has focused on coordination among European countries, generally finding that Germany had a limited leadership role among European countries prior to monetary union. (See Garcia-Herrero and Thorton (1996), Katsimbris and Miller (1993) Biltoft and Boersch (1992), Karfakis and Moschos (1990), and

\footnotetext{
${ }^{1}$ For a discussion of past literature on the benefits of international policy coordination, see Bryant et. al. (1988), Fischer (1988), Frankel and Rockett (1988), and Oudiz and Sachs (1984).
} 
Fratianni and von Hagen (1990a,b).)

It is possible that the tension between theoretical and empirical findings may reflect problems in the methodology typically employed in the empirical literature. One problem is that past studies have generally relied upon market interest rates or monetary aggregates as indicators of policy stance. But use of market data makes it inherently difficult to distinguish policy makers' intentions from demand disturbances in financial markets. As a result, the findings in some empirical studies might not indicate coordination of macroeconomic policies at all, but instead reflect the presence of exogenous financial shocks common to these countries.

A second problem is that past studies have generally relied upon vector autoregression (VAR) analysis and Granger causality tests. But this approach requires several untested assumptions on the causal structure of the vector processes involved. This paper will demonstrate some particular pitfalls of applying Granger causality tests to the issue of policy coordination, which have not previously been noted in the literature. In particular, a simulation exercise demonstrates that the complicated statistical nature of interest rate targeting distorts conventional tests based on the dynamic correlation structure between market interest rates.

This paper undertakes an empirical re-exploration of policy coordination, taking advantage of recent advances in econometric methods that avoid the particular problems listed above. Most importantly, the present paper uses data on actual interest rate targets set by each central bank rather than market rates. Hamilton and Jorda (2000) persuasively argue that the target data for the federal funds rate are an accurate reflection of the stance of mon- 
etary policy. Similar arguments can be made for the target rates that we use in this paperthey are all determined by the central bank and do not depend on demand innovations but rather on policy considerations. The data comes from the Bank of International Settlements, which recently has compiled the interest rate targets set by fourteen countries over the last two decades.

These data pose special econometric challenges. First, changes in targets are spaced irregularly in time. Second, when changes come, targets are typically modified in discrete increments rather than continuously. The measurement of these types of coordination therefore requires a newly developed class of time-series processes, called the autoregressive conditional hazard specification (ACH). Developed in Hamilton and Jorda (2000), this methodology allows one to produce forecasts of the probability of a target change, conditional on continuously updated explanatory variables, such as output growth, inflation, and the exchange rate. This paper extends this procedure to include the targets of other countries as explanatory variables, as well as indicator variables representing explicit coordination agreements. In addition, conditional on changing the target, a dynamic ordered response model allows one to measure directional coordination by analyzing how the magnitude of target changes is determined, directly allowing the effects of other countries' target changes to enter in the conditioning set.

When applied to data on policy targets for fourteen industrialized countries, the ACH methodology does identify clear signs of policy coordination over the period 1980-1998. Two clusters can be identified, each respectively led by the U.S. and Germany. Much of the coordination of European countries with Germany appears to be a response to exchange rates 
rather than a direct response to German policy per se, presumably reflecting the exchange rate arrangements of the period. The countries that coordinate with the U.S., including Germany and Japan, do so in a more direct manner, in that coordination is not simply a response to exchange rates or to domestic macroeconomic variables that happen to be similar. Finally, the results do not ascribe a large role to explicit coordination agreements, such as G-7 summits, but instead suggest that coordination tends to work through less explicit channels.

\section{Data and Descriptive Statistics}

\subsection{Data}

Analyzing whether or not there is monetary policy coordination requires a measure of policy stance that can be uniformly compared across institutions and operational frameworks. The common approach in isolating the exogenous component of a monetary indicator variable typically requires that identifying assumptions be imposed on a semi-structural model. However, there has been much recent discussion in the context of U.S. monetary models (see Rudebusch, 1998; Sims, 1998; Evans and Kuttner, 1998) regarding the meaning and usefulness of exogenous policy shocks measured via the structural VAR approach - the most common way to study this type of problem. Exogenous shocks identified under alternative specifications and methods are typically uncorrelated with one another, calling into question the precision with which the policy component is identified, outside the context of the estimated model.

By contrast, this paper adopts a much different methodology. Hamilton and Jorda (2000) propose the federal funds rate target as an alternative indicator of policy stance. The target (for short) is an internal objective unilaterally set by the Federal Reserve. This variable 
has the advantage that it is not the outcome of the interaction of reserves exchanges in the interbank market, nor is it subject to technical fluctuations in the central bank's balance sheet. Rather, it is a clear statement of the Fed's stance. We have found that a large number of central banks in the OECD often operationalize monetary policy via an indicator variable, similar in nature to the U.S. Federal funds rate target. This indicator variable is usually a target for an overnight interbank lending rate or a repurchase agreement (repo) rate and is clearly used for signalling purposes. Therefore, it is natural to take advantage of these target data in our analysis.

What justifies looking at these target rates as policy stance indicators? According to Borio (1997) and Wrase (1998) most central banks have become more market oriented in their implementation of policy, thus reducing reserve requirements (and the implicit tax these often represent to the banking system) and making liquidity management more flexible by widening the range of instruments at a bank's disposal. Consequently, as traditional open market operations carry a more muffled signal, interest rate targets have become the preferred tools with which the monetary authority transparently communicates its intentions. While there are still significant differences in the institutional framework at each central bank, ${ }^{2}$ we are confident that by focusing on interest rate targets rather than money aggregates or other market based interest rates, a sharper image on policy coordination can emerge.

The data set that we have assembled for the analysis can be divided into two broad categories: (1) high frequency, operational monetary data, typically consisting of overnight rate targets and short-term interest rates, and (2) general macroeconomic and international

\footnotetext{
${ }^{2}$ The reader is referred to Borio (1997) for a detailed description of each central bank's operating procedures.
} 
data, including GDP growth, inflation, and an exchange rate index - in other words, variables that would naturally enter a central bank's reaction function (see Taylor 1999). The final tally of countries, variables, samples and specifics are reported in Table 1. Figure 1 displays the target data along with the corresponding overnight interest rate. Here we provide a general overview.

The fourteen countries we study are: Austria (AT), Australia (AU), Belgium (BE), Canada (CA), France (FR), Germany (DE), Italy (IT), Japan (JP), Netherlands (ND), Spain (ES), Sweden (SE), Switzerland (CH), United Kingdom (UK) and the United States (US). The operational monetary data was obtained directly from the Bank of International Settlements $^{3}$. This data initially was compiled by BIS as part of an exhaustive survey: "Monetary Policy Operating Procedures in Industrial Countries" (1997) by Claudio Borio. ${ }^{4}$ According to Borio (1997), countries fall into two broad groups: (1) U.S., Canada, Australia, and Japan where the most representative policy variable is the overnight interbank rate; and (2) the remaining countries in which the policy variable is usually a tender rate applicable mainly to repos and whose maturity varies from one day to one month.

\subsection{Preliminary Views on Coordination}

Three central banks have traditionally dominated the international arena: the U.S. Federal Reserve, the Bank of Japan, and the Bundesbank (G-3). A reasonable first look at the data is to search for any evidence indicating that the central banks in our sample synchronize their target changes with the actions of these three major players. The question we ask is

\footnotetext{
${ }^{3}$ We thank Greg Sutton and the Statistical Assistance Section of the Bank of International Settlements for providing us the data.

4 The Macro-International data was obtained from the IFS database.
} 
therefore: Does the probability that a given country will change its target depend on whether or not there was a target change in either of the Japanese, German or American interest rate targets?

Let $x_{t}^{i}=1$ if in period $t$, the target was changed in country $i, 0$ otherwise. The per-period probability conditional on the actions of the G-3 can be expressed as a discrete time hazard, $h_{t}^{i}=P\left(x_{t}^{i}=1 \mid x_{t}^{U S}, x_{t}^{J P}, x_{t}^{D E}\right)$. A simple way to compute this hazard is with the logistic transform,

$$
\begin{aligned}
& h_{t}^{i}=\frac{1}{1+e^{\lambda_{t}^{i}}} \\
& \lambda_{t}^{i}=\omega+\beta^{U S} x_{t}^{U S}+\beta^{J P} x_{t}^{J P}+\beta^{D E} x_{t}^{D E}
\end{aligned}
$$

with log-likelihood

$$
L(\theta)=\sum_{t=1}^{T} x_{t}^{i} \ln \left(h_{t}^{i}\right)+\left(1-x_{t}^{i}\right) \ln \left(1-h_{t}^{i}\right)
$$

Table 2 reports the average hazard $\bar{h}^{i}$ for each country and the change in the hazard caused by changes in the G-3 targets. We organize the data into two frequencies, weekly and monthly, so as to match the timing and length of the maintenance periods common in the countries that we consider.

The results in Table 2 suggest two of the three major central banks exert a fair amount of influence. For example, Austria changes its target, on average, once every 25 weeks. However, if there is a change in the German Lombard rate, the probability of a target change increases to a 1 in 4 chance. Similarly, Canada shows strong ties to the U.S. While the average frequency of target changes is once every 8 weeks, there is a $70 \%$ chance of a 
change if the U.S. also changed its target during that week. With a few exceptions, there aren't big differences between the weekly and monthly frequencies. Perhaps the three more interesting cases are Germany, Spain and the U.K. which, at a monthly frequency, show significant dependency on Japan, Germany and the U.S. respectively. According to this preliminary analysis we can group countries as follows:

- U.S. Area: Australia, Canada, U.K. (maybe Italy).

- German Area: Austria, Belgium, France, Netherlands (maybe Spain).

- Japanese Area: (maybe Germany).

- Not connected: Switzerland, Japan, Sweden, U.S.

It is not surprising that Germany's group includes a list of countries that often have been characterized as the "European core." Italy's absence from this listing may reflect the fact that our data sample for this country (May 1991 - July 1998) is dominated by Italy's absence from the EMS following the 1992 crisis. The U.S. group notably includes the English speaking countries of our sample. Note that at this stage we are unable to detect significant coordination among the G-3 economies of Germany, Japan and the U.S.

The last group of countries deserves additional comment. Switzerland's measure of monetary policy is the flexible Lombard rate, although the primary focus of the central bank is the volume of giro deposits. Borio (1997) thus suggests that "[...] interest rates are of limited significance in conveying policy intentions." (p. 17). Similarly, Japan is the only country that is still using a quantitative signal as a key mechanism for steering an interest rate operating target. Sweden uses a combination of a target for interest rate tenders with variable interest 
rate auctions when markets fluctuate around desirable levels (this mechanism is similar to that used by the Bundesbank).

Although these results are suggestive, it is difficult to discern at this point what motivates these interconnections. One explanation could simply be that each group of countries tends to face similar shocks, and that policy makers in each country are simply responding to domestic economic conditions without any real coordination. Alternatively, countries may be acting simultaneously in response to exchange rate fluctuations due to asymmetric shocks. This potentially may reflect the presence of international exchange rate arrangements or simply a domestic preference for stable exchange rates. Our approach in the following sections will be to try to describe each central bank's policy rule and choice of response timing. If, after controlling for responses to a range of domestic macroeconomic factors, we are unable to control for the timing component, we conclude we have evidence of direct policy coordination.

\section{Interest Rate Dynamics, Target Setting and Coordination}

This study employs a more suitable data set and more adequate econometric techniques than previous studies of coordination. This section in particular, demonstrates that the interest rate target-setting behavior of the central banks in our sample, modifies the statistical properties of the overnight rates and thus renders conventional VAR and Granger Causality measures of coordination inoperative.

In this paper, we define two types of coordination after controlling for domestic and international factors: coordination in the timing with which central banks adjust their targets, and coordination in the direction in which the targets are adjusted. Target rates are adjusted infrequently and typically by discrete increments rather than by a continuous amount, thus 
complicating the analysis. We discuss some of these complications below.

Analyses based on the dynamic comovement of market interest rates can be deceiving for several reasons. For example, it is conceivable that two countries coordinate the timing of their actions, typically adjusting their targets in the same direction in response to common, real economy shocks (such as an oil shock) but adjusting their targets in opposite directions in response to financial shocks that distort their exchange rate. The averaging of these two responses that would be common in VAR-based measures would thus tend to mask any appearance of coordination. Conversely, most interest rate data have a root at or near unity. It is conceptually difficult to justify that interest rates have a unit root. However, from a statistical point of view, this calls into question issues of spurious regression and cointegration which are not commonly discussed in empirical studies of coordination.

These considerations aside, central bank, interest rate, target-setting behavior imbues statistical characteristics in the interest rate data that make coordination difficult to detect, even in the most favorable of scenarios. Rudebusch (1995) demonstrated in a clever simulation, that the manner the U.S. Federal Reserve adjusts the federal funds rate target, justifies the poor results obtained in traditional term structure regressions. In this section, we demonstrate with an exercise similar in spirit to Rudebusch's, that interest rate based measures of dynamic comovement are poorly suited to uncover the relationships that may exists among central banks.

Let $r_{t}^{A}$ and $r_{t}^{B}$ denote the overnight rate in countries $\mathrm{A}$ and $\mathrm{B}$, respectively. Although central banks choose a target level for the overnight rate, they have only imperfect control over it. Therefore, the overnight rate tends to fluctuate around the target level. In the U.S., 
these deviations typically amount to only a few basis points and tend to be short lived (see Hamilton (1996)). Accordingly, we model the overnight rate as,

$$
r_{t}^{i}=\bar{r}_{t}^{i}+\varepsilon_{i t} \quad \varepsilon_{i t} \sim N\left(0, \sigma_{i}^{2}\right) \quad i=A, B
$$

where $\bar{r}_{t}^{i}$ denotes the target overnight rate. In practice, the residuals, $\varepsilon_{i}$, may be a general stationary sequence, but to keep the exercise simple, we will simulate them as i.i.d. normal random variables. The process by which the target is adjusted is described by,

$$
\bar{r}_{t}^{i}=\left(1-x_{t}^{i}\right) \bar{r}_{t-1}^{i}+x_{t}^{i}\left(\bar{r}_{t-1}^{i}+\Delta \bar{r}_{t}^{i}\right)
$$

where $x_{t}^{i}=1$ if the target is changed in period $t, 0$ otherwise, and $\Delta \bar{r}_{t}^{i} \in\left\{k_{1}, k_{2}, \ldots, k_{m}\right\}$, reflecting the fact that changes in the target are done in discrete increments. Each period, there is some probability that the target will be changed, $h_{t}^{i}=P\left(x_{t}^{i}=1 \mid \Omega_{t-1}\right)$, which can be interpreted as a discrete time hazard. Similarly, conditional on changing the target, the magnitude of the change, $k_{j}$, can be described by,

$$
P\left(\Delta \bar{r}_{t}^{i}=k_{j} \mid x_{t}^{i}=1, \Omega_{t-1}\right)=P\left(c_{j-1}<\Delta r_{t}^{i *}<c_{j} \mid x_{t}^{i}=1, \Omega_{t-1}\right) \quad j=1,2, \ldots, m
$$

with $c_{0}=-\infty, c_{m}=\infty$, and $\Delta r_{t}^{i *}$ an auxiliary latent index. To complete the simulation, we specify a simple bivariate model for $h_{t}^{i}$ that will capture the coordination in the timing and a bivariate model for $\Delta r_{t}^{i *}$ that will capture coordination in the direction of the change. First, note that $h_{t}^{i} \in[0,1]$ since it is a probability, hence,

$$
\begin{aligned}
& h_{t}^{i}=\frac{1}{1+e^{\lambda_{t}^{i}}}
\end{aligned}
$$

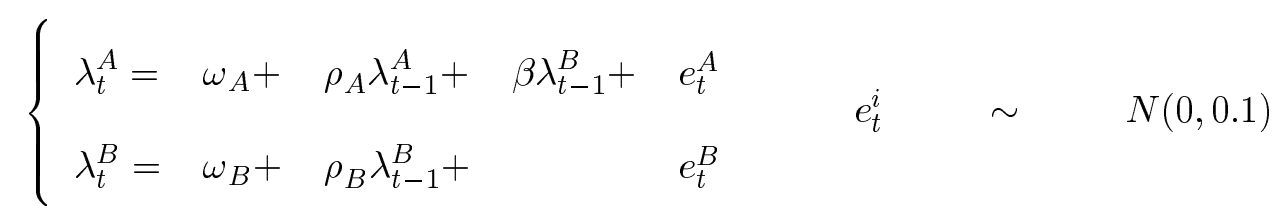


so that $x_{t}^{i}=1$ if $h_{t}^{i}>u_{t}^{i}$, 0 otherwise, where $u_{t}^{i}$ is a uniform [0,1] random variable. The bivariate specification in (4) makes explicit two important features: (1) persistence in target changes, which as we shall see in later sections, is a common feature in our data set, and (2) policy setting in country A depends, via the parameter $\beta$, on country B's policy setting. If $\beta>0$, the likelihood of a target change in $\mathrm{A}$ increases with the likelihood of a target change in country $\mathrm{B}$. If $\beta=0$, target setting occurs independently, and if $\beta<0$, country B's likelihood of a change reduces the likelihood that country A will change its target.

Similarly, to capture any coordination in the direction of changes in the target that may occur independently from coordinating the timing, consider the following bivariate model,

$$
\left\{\begin{array}{llll}
\Delta r_{t}^{A *} & =\gamma_{A} \Delta r_{t-1}^{A *}+\psi \Delta r_{t-1}^{B *} & + & v_{t}^{A} \\
\Delta r_{t}^{B *} & =\gamma_{B} \Delta r_{t-1}^{B *}+ & & +v_{t}^{B}
\end{array} \quad v_{t}^{i} \sim N(0,1)\right.
$$

The parameters $\gamma_{i}$ capture persistence in the direction of target changes, which is also a commonly observed feature of the data, and the parameter $\psi$ makes explicit the correlation in the direction in which the targets in countries $\mathrm{A}$ and $\mathrm{B}$ are changed. If $\psi>0$, countries $\mathrm{A}$ and $\mathrm{B}$ tend to change their targets in the same direction, if $\psi=0$, there is no relation and if $\psi<0$, changes in the target tend to be in opposite directions.

The basic setup described in equations (1)-(5) establishes a well-defined hierarchy: while decisions on country B's target are based completely on domestic information, country A's target timing and magnitude of changes depend on previous actions by country B whenever $\beta$ and $\psi$ are non-zero, that is, B Granger-causes A. Table 3 contains the results of a simple Monte-Carlo exercise in which simulated overnight rates are generated for different parameter values, ${ }^{5}$ using equations (1)-(5). For each combination of parameters, we generate 100 series

\footnotetext{
${ }^{5}$ The choice of parameter values reported in Table 3 roughly corresponds to parameters that would generate
} 
of length 400, where the first 100 observations are deleted to avoid initialization problems and with initial values, $\bar{r}_{t}^{A}=\bar{r}_{t}^{B}=5 \%$. Then, on each of the series, we perform a standard Granger-causality test, collect the p-value of all these tests and report the Monte-Carlo average. Figure 2 depicts an example of the simulated series.

Several results deserve comment. The most immediately apparent is the extraordinary sensitivity of the Granger-causality test. Even in the quasi-ideal scenario in which there is substantial coordination in the timing $(\beta=0.75)$ as well as coordination in the direction $(\psi=0.75)$, Granger-causality tests will routinely fail to pick up these features whenever the frequency with which the target is changed is relatively low (below $30 \%$ of the time) and/or the central bank's control of the overnight rate around the target is poor $\left(\sigma_{\varepsilon}>0.25\right)$. Other features of the model appear to be less important in determining this sensitivity except perhaps the degree of persistence in the direction of the target changes $\left(\gamma_{A}\right.$ and $\gamma_{B}$ small $)$. It is important to note that this failure of the Granger-causality test can occur under the most favorable of situations, with high values of the parameters $\beta$, and $\psi$, with a relatively precisely controlled overnight rate and with realistic parameters values. The Granger-causality test metric appears to be well suited to capture directional coordination since it will detect this type of coordination in the absence of coordination in the timing as long as the target is changed sufficiently often ( $40 \%$ of the time and above). However, even when the timing of target changes is strongly related $(\beta=0.99)$, as the value of $\psi$ decreases, even slightly (from 0.75 to 0.5 and below), the Granger-causality test will fail to pick the relationship. interest rate series with properties similar to the U.S. federal funds rate. 


\section{The Econometrics of Interest Rate Targets}

There is substantial agreement in the literature that investigates monetary policy rules (see Taylor, 1999), that the manner in which central banks determine the level of interest rates can be well described by the following type of rule,

$$
r_{t}^{*}=\bar{r}+\beta_{y} y_{t}^{*}+\beta_{\pi}\left(\pi_{t}-\pi^{*}\right)
$$

where $\bar{r}$ is the equilibrium interest rate, $y_{t}^{*}$ is the output gap, and $\pi^{*}$ is the target level for inflation. This framework, popularized by Taylor (1993), succinctly summarizes the monetary authority's reaction function to variations in the output gap and inflation and can be easily generalized to include the exchange rate if, for example, we were thinking of a small open economy. More sophisticated variations of the rule in (6) include specifications based on lagged information, forecasts of the future value of the different variables, etc. Although this type of rule appears to fit the data reasonably well, in practice, central banks do not continuously modify their targeted level of interest rates. Rather, as Rudebusch (1995) and Hamilton and Jorda (2000) document, the targets are seldom changed, and when they are changed, it is in discrete increments. Section 2 presented evidence suggesting that conventional measures of dynamic association on interest rate data depend critically on whether or not there is directional coordination but remain silent as to whether or not there is coordination in the timing.

A natural way to present the stochastic process that describes how interest rate targets are set for country $i$ is,

$$
r_{t}^{i}=\bar{r}_{t}^{i}+\varepsilon_{t}^{i} \quad\left\{\varepsilon_{t}^{i}\right\} \text { is a stationary sequence }
$$




$$
\bar{r}_{t}^{i}=\left(1-x_{t}^{i}\right) \bar{r}_{t-1}^{i}+x_{t}^{i}\left(\bar{r}_{t-1}^{i}+\Delta \bar{r}_{t}^{i}\right)
$$

where $\Delta \bar{r}_{t}^{i} \in\left\{k_{1}, . ., k_{m}\right\}$ is the discrete set of changes that describe the manner the target is changed. The probability models that describe how central banks choose the timing and magnitude of target changes can be generically expressed as

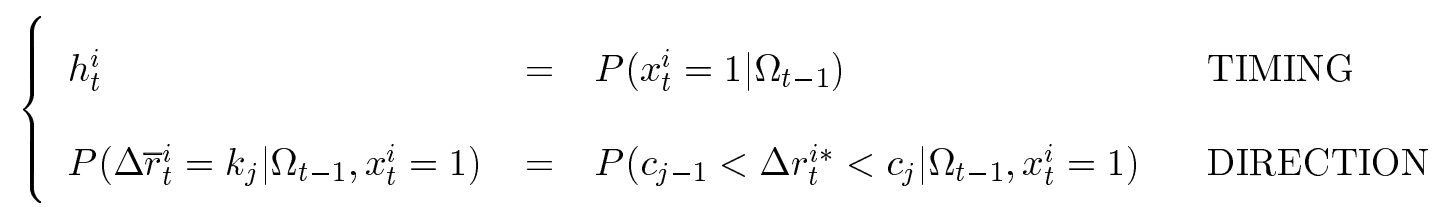

where all the variables have been defined above. The next sections describe the specific formulations of the probability models in (7).

\subsection{The Timing of Target-Setting}

The problem of describing when the central bank decides to change the target can be viewed as a conventional duration process in discrete time. It is preferable to choose a discrete-time model over a more traditional continuous-time duration model because the conditioning set will include such variables as inflation, output, exchange rate, etc. whose values are updated on a regular basis with each new release rather than remaining constant between target changes. Therefore, the conditional hazard $h_{t}^{i}=P\left(x_{t}^{i}=1 \mid \boldsymbol{\Omega}_{t-1}\right)$, can be modeled using the ACH model introduced in Hamilton and Jorda (2000). In particular, think of the underlying process that generates $x_{t}^{i}$ as a linear general dynamic process,

$$
\lambda_{t}^{i}=\omega^{i}+\sum_{l=1}^{p} \alpha_{l}^{i} u_{s(t-l)}^{i}+\sum_{l=1}^{q} \beta_{l}^{i} \lambda_{s(t-l)}^{i}+\gamma^{i \prime} \mathbf{w}_{t-1}
$$

where $\omega, \alpha, \beta$, and $\gamma$ are parameters, $\lambda_{s(t-l)}$ is latent index, $u_{s(t-l)}$ denotes the amount of time that elapsed between the two most recent target changes as of time $t-l, \mathbf{w}_{t-1}$ is a vector of exogenous and predetermined variables and $s(t-l)$ is a time index denoting the $s^{\text {th }}$ most 
recent event as of time $t-l$ and therefore, allows us to date variables in event time rather than in calendar time.

The conditional hazard $h_{t}^{i}$ is a probability and as such, it is bounded between 0 and 1 . Thus, to close the specification, an optional specification of the ACH explored in Demiralp and Jorda (2001) consists on taking the logistic transform on $\lambda_{t}^{i}$, such that,

$$
h_{t}^{i}=\frac{1}{1+e^{\lambda_{t}^{i}}}
$$

The log-likelihood for the problem can then be trivially expressed as,

$$
L_{1}\left(\theta_{1}\right)=\sum_{t=p}^{T}\left\{x_{t}^{i} \ln \left(h_{t}^{i}\right)+\left(1-x_{t}^{i}\right) \ln \left(1-h_{t}^{i}\right)\right\}
$$

which can be maximized by traditional numerical techniques. Given this general formulation of the problem, we then selected two types of variables for each country in our sample. First, we selected variables conventionally used to describe the central bank's choice of monetary policy, namely, data on output growth, (typically measured by the log growth of the industrial production index so as to maximize the frequency of observation); inflation measured by the consumer price index; and exchange rates given by the nominal effective exchange rate. All three variables are at a monthly frequency and were obtained from International Financial Statistics. The second type of variables are designed to capture any coordination in the timing with which the G-3 central banks change their targets and they measure a transformation of the length of time since the most recent action taken by any of the G-3.

Consequently, the specification for the latent process $\lambda_{t}^{i}$ described in (8) is:

$$
\begin{aligned}
\lambda_{t}^{i}= & \omega^{i}+\alpha_{1}^{i} u_{s(t-1)}^{i}+\beta_{1}^{i} \lambda_{t-1}^{i}+\gamma_{y^{+}}^{i} \tilde{y}_{t-1}^{+}+\gamma_{y^{-}}^{i} \tilde{y}_{t-1}^{-}+ \\
& \gamma_{\pi^{+}}^{i} \pi_{t-1}^{+}+\gamma_{\pi^{-}}^{i} \pi_{t-1}^{-}+\gamma_{e^{+}}^{i} e_{t-1}^{+}+\gamma_{e^{-}}^{i} e_{t-1}^{-}+
\end{aligned}
$$




$$
\phi_{u s}^{i} D_{t-1}^{u s}+\phi_{j p}^{i} D_{t-1}^{j p}+\phi_{d e}^{i} D_{t-1}^{d e}
$$

where

$$
D_{t}^{j}=\left(1+\exp \left(\frac{z_{t}^{j}}{\bar{z}^{j}}\right)\right)^{-1}, j=\{U S, J P, D E\}
$$

We now comment on the properties of this specification. The constant term, $\omega^{i}$, absent anything else, would determine the average hazard - the average frequency with which the target is changed in country $i . u_{s(t-1)}$ is the duration elapsed between the two most recent changes in country $i^{\prime} s$ target as of time $t-1$. Therefore, a positive value for $\alpha_{1}^{i}$ suggests that there is a higher probability that the target will be changed if it took a long time to modify the target between the previous two changes. $\beta_{1}^{i}$ measures the degree of persistence in changing the target, but more importantly, it allows for the effect of the explanatory variables to be dynamic in a parsimonious way by determining the exponential rate at which the influence of the exogenous variables decays. ${ }^{6}$

The term $\tilde{y}_{t-1}^{+}$is a dummy variable indicating times when the output gap is positive, where the gap is measured as the percentage deviation of industrial production from a log-linear trend. The term $\tilde{y}_{t-1}^{-}$is a dummy variable indicating times when the output gap is negative. Consequently, $\gamma_{y^{+}}^{i}$ and $\gamma_{y^{-}}^{i}$ measure the sensitivity of the monetary authority to deviations from trend growth which may be possibly asymmetric. Similarly, $\pi_{t-1}^{+}$is a dummy variable indicating when CPI inflation is above a $2 \%$ optimal level, and $\pi_{t-1}^{-}$indicates when inflation is below this target. Lastly, $e_{t-1}^{+}$indicates when is the percentage change in the nominal effective exchange rate index is positive, so that the domestic currency is appreciating in value; $e_{t-1}^{-}$indicates when is the domestic currency is depreciating.

\footnotetext{
${ }^{6}$ See Hamilton and Jorda (2000).
} 
Finally, the variable $D_{t}^{j}$ for $j=U S, J P, D E$ described in (10) is a semiparametric indicator of the deviation of the event probability from mean of the number of days since the last change in the $j^{\text {th }}$ country's target rate. Note that $z_{t}^{j}$ measures the number of days as of day $t$, of the most recent change in country $j^{\prime} s$ target. The variable $D_{t-1}^{i}$ will be near zero if a leader country has not been actively changing policy, and it will increase the more recently the leader country has changed policy. As a result, a significant value for the coefficient $\phi_{j}$ indicates that, once domestic and foreign factors are taken into account, the timing of target changes is influenced by the $j^{\text {th }}$ central bank's choice of target adjustments. In particular, a negative value of this coefficient would indicate that a change in the policy of a leader country makes it more likely for the country under consideration to also change its policy. This is because a rise in $D_{t-1}^{j}$ lowers the latent variable, $\lambda_{t}^{i}$, which raises the probability of a policy change since the hazard rate, $h_{t}^{i}$ equals $\left(1+\exp \left(\lambda_{t}^{i}\right)\right)^{-1}$.

It is important to highlight the reasoning behind the choice of how the dependent variables are entered into equation (9). Notice that the object of the model is to forecast the central bank's decision to change the target. Consequently, the effect of the variables on this decision is not that which is typical in a regression model: presumably, central banks are as likely to react to a bad figure for output (suggestive that easing of interest rates may be needed) as they are likely to react to a good figure for output (suggestive that more aggressive monetary policy is needed). This justifies our partition of the variable in question into positive and negative deviations from a baseline level. The magnitude of these deviations is less critical since at this point we are only concerned with modeling the decision to act or remain inactive. The next section emphasizes the choice of action (raising versus lowering interest rates and 
by how much) and as we shall see, requires that we exploit the information of the explanatory variables in a much more conventional way.

\subsection{The Direction of Target-Setting}

Conditional on changing the target, the central bank then needs to choose how much to change interest rates by. This is typically done in discrete increments rather than in a continuous manner and therefore, it is natural to represent this behavior with an ordered response model (this corresponds to the second line in equation 7 ). Note that since we are conditioning on the target being changed (i.e. $x_{t}^{i}=1$ ), this ordered response model is specified in event time rather than in calendar time. This feature provides a significant advantage: our focus becomes interest rate movements initiated by the monetary authority, that is, the snapshots provided by episodes in which the target was changed. Therefore, any intervening fluctuation of interest rates between target changes generated by demand disturbances and other technical factors not associated with actual monetary policy objectives, is automatically filtered out. Market interest rates measured in calendar time by contrast, mix monetary authority's policy movements with demand innovations, substantially adding noise to any measure of coordination, thus viciating the quality of conventional measures based on the dynamic correlations.

The specification of the conditional mean of the latent index in the ordered response model is based on the same explanatory variables as the ACH model (i.e. the model for the timing) and therefore can be expressed as,

$$
\begin{aligned}
P\left(\Delta \bar{r}_{t}^{i}\right. & \left.=k_{j} \mid \Omega_{t-1}, x_{t}^{i}=1\right)=P\left(c_{j-1}<\Delta r_{t}^{i *}<c_{j} \mid \Omega_{t-1}, x_{t}^{i}=1\right) \\
\Delta r_{t}^{i *} & =\delta_{y}^{i} y_{t-1}^{i *}+\delta_{\pi}^{i}\left(\pi_{t-1}^{i}-\pi^{*}\right)+\delta_{e}^{i} e_{t-1}^{i}+
\end{aligned}
$$




$$
\begin{aligned}
& \theta_{u s} \Delta \bar{r}_{s(t-1)}^{u s}+\theta_{d e} \Delta \bar{r}_{s(t-1)}^{d e}+\theta_{j p} \Delta \bar{r}_{s(t-1)}^{j p}+\varepsilon_{t}^{i} \\
= & \Psi^{i \prime} \mathbf{m}_{t-1}^{i}+\varepsilon_{t}^{i}
\end{aligned}
$$

The specification in (11) simply states that changes in country $i^{\prime} s$ target, $\Delta \bar{r}_{t}^{i}$, can take only the collection of values in the set $\left\{k_{1}, k_{2}, \ldots, k_{m}\right\}$ according to the value of the conditional mean for the index $\Delta r_{t}^{i *}$. This conditional mean is specified as a linear function of: the output gap for country $i, y_{t-1}^{i *}$, measured as percent deviations from a log-linear trend; deviations of country $i^{\prime} s$ inflation rate from a $2 \%$ target rate, $\left(\pi_{t-1}^{i}-\pi^{*}\right)$; the percentage change in the nominal effective exchange rate for country $i, e_{t-1}^{i}$; and the size of the most recent target change as of date $t-1$ in the U.S., Germany, and Japan, namely, $\Delta \bar{r}_{s(t-1)}^{u s}, \Delta \bar{r}_{s(t-1)}^{d e}$, and $\Delta \bar{r}_{s(t-1)}^{j p}$

It is worth clarifying several points. First, we have indexed the dependent latent index and most of the explanatory variables using the calendar index $t$. Note however, that the response model is only defined when $x_{t}^{i}=1$, which highlights why the process evolves in event time rather than in calendar time. Consequently, when a regressor has the time index $t-1$, it refers to information available the calendar period prior to the target change. We preferred maintaining the index $t$ so as not to add an unnecessary layer of notation.

Secondly, the index chosen for the variables $\Delta \bar{r}_{s(t-1)}^{u s}, \Delta \bar{r}_{s(t-1)}^{d e}$, and $\Delta \bar{r}_{s(t-1)}^{j p}$ registers the magnitude of the most recent change in the U.S., German and Japanese targets as of time $t-1$. Notice that unless these targets were coincidentally changed at time $t-1$, these changes would therefore be zero. Thus, the notation $s(t-1)$ used in the ACH model makes explicit that our concern is with the magnitude of the most recent target changes, irrespective of when they were changed. Finally, unlike the timing ACH model, the regressors in the 
ordered response model enter linearly. High values of the conditional mean, $\Delta r_{t}^{i *}$, translate into positive changes in the target having a higher probability than negative changes and vice versa. For example, if $\delta_{\pi}^{i}>0$, positive deviations of inflation above target will make the conditional mean higher and thus $\Delta \bar{r}_{t}^{i}>0$ more likely whereas values of inflation below target will reduce the conditional mean and make $\Delta \bar{r}_{t}^{i}<0$ more likely.

The model in equations (11) and (12) requires that we make a distributional assumption in order to specify the log-likelihood function. We follow the empirical literature in this respect and assume Gaussianity so that the likelihood is given by,

$$
L_{2}\left(\theta_{2}\right)=\sum_{\left\{x_{t}^{i}=1\right\}_{t=1}^{T}} \sum_{j=1}^{m} \ln \left[\Phi\left(c_{j}-\Psi^{i \prime} \mathbf{m}_{t-1}^{i}\right)-\Phi\left(c_{j-1}-\Psi^{i \prime} \mathbf{m}_{t-1}^{i}\right)\right]
$$

where $c_{0}=-\infty\left(\right.$ and thus $\left.\Phi\left(c_{0}-\Psi^{i \prime} \mathbf{m}_{t-1}^{i}\right)=0\right), c_{m}=\infty\left(\right.$ and thus $\left.\Phi\left(c_{m}-\Psi^{i \prime} \mathbf{m}_{t-1}^{i}\right)=1\right)$ and the parameters $c_{1}, \ldots, c_{m-1}, \Psi^{i \prime}$ are estimated by maximizing (13) with conventional numerical techniques. In addition and to homogenize somewhat the discrete nature of target changes across countries, we restricted the number of categories to four, which can be loosely interpreted as: $k_{1}=$ strong decrease, $k_{2}=$ decrease, $k_{3}=$ increase, $k_{4}=$ strong increase. For example, in the U.S. these categories would correspond to the following values: $k_{1}=-0.5$, $k_{2}=-0.25, k_{3}=0.25, k_{4}=0.5$. Table 4 below reports for each country, how changes in the target are reclassified.

\section{Results}

\subsection{Timing Model: European Coordination}

Table 5 shows results for ACH estimation of the timing model for the fourteen countries. The macroeconomic variables are significant for several countries, reflecting the important role that inflation, output gaps, and exchange rates play in the setting of monetary policy 
targets. One striking observation is that the group of countries that coordinates directly with Germany completely evaporates. The Netherlands is the only country with a significant coefficient on the German policy variable, and the sign of this coefficient oddly is positive. Given the specification of the estimation equation, this implies that once we control for other macroeconomic variables, a recent change in German policy makes a subsequent change in Dutch policy less likely rather than more likely. This result stands in contrast to the large group of countries that appeared to coordinate with Germany in the logit results in section 2.2. Two of the European countries previously in the Germany group, France and Austria, show a significant response toward industrial production and the exchange rate now instead of toward German policy. Given the role of industrial production, one implication is that part of the apparent coordination observed in the previous section may have been illusory. Monetary policy in France and Austria were responding to domestic economic conditions, and it so happened that business cycles in these two countries in many ways resemble those in their common neighbor, Germany.

Given the significant coefficients on the exchange rate, another implication is that France and Austria were in part acting to stabilize their exchange rates, perhaps as part of their role in the EMS and ERM. This is quite plausible for France, since it was a long-standing member in European exchange rate arrangements. Since Austria joined the ERM late in our sample, it may indicate Austria was using monetary policy to stabilize its exchange rate well before it was part of this mechanism, or it simply had preferences for a stable exchange rate. While conceptually distinct from the type of direct policy coordination we are seeking, this still may be regarded as a type of policy coordination, and it is not difficult 
to consider a case in which this could erroneously be picked up by our simple logits as coordination. Suppose Germany has changed its monetary policy target in response to large domestic shocks, such as unification, and suppose these neighboring countries have adjusted their targets to maintain a stable effective exchange rate level. This would imply these neighboring countries would adjust their monetary policies in similar direction to that undertaken by Germany. It should also be noted that our estimates here by definition will not pick up cases of sterilized intervention, since we focus only on cases where the target interest rate was actually changed. Further, while it would be interesting to estimate the model over various subsamples here, the data we use limits us in this regard, since the target rate data is available for fairly short periods for many countries.

The results also offer additional insight into the workings of the ERM during the sample period. One is that the ERM was not as one-sided as the story above might indicate, in that German policy responded to exchange rates, just as did its neighbors. True, Germany's most significant response is toward its domestic CPI, but the estimates also indicate a very significant response to exchange rate as well. The estimates do not permit us to gauge the relative magnitude of German and French responses to exchange rates, since the values here simply measure the probably of a response without reference to the size of this response.

\subsection{Coordination with the U.S.}

Results on coordination with the U.S. show an interesting contrast with those on coordination within Europe. While introducing macro variables and dynamics appeared above to reduce the direct coordination in Europe, it elicits a greater degree of coordination with the U.S. In contrast to the simple logits of Table 2, Table 5 now shows clear coordination among the 
G-3 countries. Both Germany and Japan appear to respond to German policy when setting their monetary policy targets. One explanation would be that these countries experience quite different shocks from the U.S., so that their monetary policy actions in general differ from those in the U.S. But once these domestic reactions are removed, the remaining policy actions left unexplained by domestic factors do coincide with policy actions taken in the U.S.

It is true, on the other hand, that the UK and Australia now appear not to coordinate with the U.S. Again the likely explanation is that these economies, which share a more Anglo economic structure, may be responding to domestic shocks that happen to be more similar to those in the U.S., rather than indicating actual coordination. These two countries also respond significantly to the exchange rate, so it is possible their apparent coordination with the U.S. reflected a concern to maintain a stable exchange rate, since the U.S. is a large trading partner.

As in the case of European coordination, coordination with the U.S. is not completely one sided. It is true that results do not indicate the U.S. responds directly to the policies of Germany or Japan, so that in this sense it satisfies the definition of a leader of the G3 group. However, it does respond very significantly to the exchange rate, and as discussed above, this could be interpreted to indicate a type of indirect coordination with other countries. The only other country in our sample beside the U.S. to show no direct coordination with any other country in any of our estimations is Switzerland.

The results show one other interesting observation with regard to exchange rate intervention. Far more countries appear to respond with unsterilized intervention in the case where the nominal effective exchange rate is rising than when it is falling, and in those countries 
that respond to exchange rate changes of both directions, the result is more significant for positive changes. Given that the exchange rate is measured here as an index, this indicates cases where the currency is appreciating. This may indicate a greater willingness to intervene, or simply a greater willingness to forego sterilization when intervening against an appreciating domestic currency.

\subsection{Formal Agreements}

Given that we find evidence of direct policy coordination, it is reasonable to ask whether this can be ascribed to formal coordination agreements. This is a question that has been addressed in recent work by Dominguez (1997), and we utilize the data set she compiles on the timing of official coordination agreements. Dominguez studied the communiques produced from meetings of the G7, G-5 and G3 dating from 1975 to 1993, and identified when there was a call for a coordinated effort to reduce inflation or lower interest rates. As described by Dominguez, commitments to fight inflation coincide with periods where actual inflation is rather high, beginning with the first summit in 1975 through the London Summit in 1984, and again from mid 1988 to April 1989. The focus shifted to economic growth and commitments to lower interest rates in 1986, 1987, 1991 and 1992. Overall, Dominguez identifies in the sample fifteen cases of commitments to lower inflation and nineteen commitments to lower interest rates.

We incorporate Dominguez's listings into our ACH estimation methodology. One difference is that we can only use her series back to 1980 at the most, given that our target rate series at most go back this far. Also, given that the ACH methodology does not distinguish between expansionary and contractionary policy shifts, we combine the two types of agree- 
ments into a single dummy variable. This dummy is a monthly series that takes a value of 1 during a month were a summit calls for coordinated action of any type. (Note that the ACH methodology allows for a complex lag structure that can accommodate persistent effects of summit meetings on policy decisions in the months following a summit.)

Table 6 shows result for the G-5 countries. These particular countries were tested, primarily because they were the only ones with target data series going back sufficiently far to make the exercise feasible, given that the Dominguez variable ends already in 1993. As can be seen in the table, we can detect a response to the agreement dummy variable only for the case of France, and not for the other four countries. This is despite the fact that we still pick up significant coordination with the U.S. for the cases of Germany and Japan. We conclude that coordination may well work through other, less official channels than formal agreements. Alternatively, since we are controlling already for inflation and output gaps in our estimation, and the agreements typically correspond with times when these two variables are problematic for these countries, the effects of the dummies in our estimation may be diluted.

\subsection{Results of the Directional Model}

While the ACH results discussed above can be used to measure the probability of a policy change, they are silent when it comes to questions of how large these policy changes are, or whether these changes are sensible in terms of sign. To investigate these particular aspects of coordination, we employ a different but more familiar methodology, that of ordered probits.

Results of the timing model estimations are presented in Table 7. Our first task is to confirm that our data implies sensible signs for policy responses. Seven of the countries show 
a significant response to the nominal exchange rate index, and six of these coefficients are negative. This result is sensible, since it implies that when the domestic currency has been appreciating, countries tend to respond by lowering the interest rate target. All five cases of significant response to industrial production are positive. This too is sensible, implying that countries respond to unusually strong growth by raising their interest rate target. More puzzling is the fact that a number countries appear to lower their interest rates in response to unusually high CPI inflation. One explanation is that central banks respond to anticipated future inflation more than to lagged or current inflation, and the positive response to industrial production growth rates reported above may be capturing this effect. Finally, the responses to foreign policy variables are almost all positive, which is sensible, indicating that countries tend to move in the same direction as their policy leader.

A second issue to investigate is a question that arose in section 5.1 above. We found that Germany had a significant response to the exchange rate as did other members of the European Exchange Rate Mechanism, suggesting a more symmetric relationship in the ERM than was previously thought. Ordered probit results again show a German response to exchange rates that is statistically significant, but now we see that the magnitude of this response is much less than that of any of the other European countries who show a statistically significant response to the exchange rate. In particular, the Germany response coefficient of -0.24 is much less (in absolute value) than the -0.62 coefficient for France.

Next we note that the groupings by leader are in some ways different from that suggested by the ACH results. Most prominently, the group of countries coordinating directly with Germany is larger, now including Austria, Belgium France, Italy, the Netherlands, Spain 
and the U.K. Although the exchange rate is included in these regressions, the ordered probit methodology seems less able to pick up the responses to this variable than was the ACH methodology, and this may explain why there is more direct coordination left after controlling for the exchange rate. Also, the group coordinating with the U.S. is smaller, including only Germany, and perhaps Japan, which is just on the far side of significance at the $90 \%$ level.

Finally, we can measure which countries in Europe respond most strongly to the German lead. The coefficients on German policy are strongest for Austria and Italy, followed by France and Spain. It is also notable that Germany appears here to coordinate with Japan as well as with the U.S., with coefficients similar in magnitude.

\section{Conclusion}

This paper has re-examined the issue of international macroeconomic policy coordination, taking advantage of recent developments in empirical methods used in the closed-economy literature to study monetary policy rules. This methodology, referred to as the Autoregressive Conditional Hazard model, allows us to make effective use of data on actual policy targets set by central banks, rather than relying on interest rates set in the marketplace. This allows us to filter out the effects of demand shocks in financial markets, and focus directly on the intentions of policy makers. We also avoid some pitfalls of VARs and Granger Causality tests, which we demonstrate can mask coordination that is present in the data.

When applied to data on policy targets for fourteen industrialized countries, the ACH methodology does identify clear signs of policy coordination over the period 1980-1998. Further, two clusters can be identified, respectively led by the U.S. and Germany. Much of the coordination of European countries with Germany appears to be a response to exchange rates 
rather than a direct response to German policy per se, presumably reflecting the exchange rate arrangements of the period. We also detect a cluster of countries that coordinate with the U.S., including Germany and Japan. This coordination of macro policies appears to be more direct, in that it cannot be attributed to countries responding to exchange rates or to domestic macro variables that happen to be similar. Finally, the results do not ascribe a large role to explicit coordination agreements, such as G-7 summits, but instead suggest that coordination tends to work through less explicit channels.

This evidence stands in contrast to the recent theoretical re-exploration of international policy coordination. While recent work adopting the microfoundations of the "new open economy macroeconomics" does find potential benefits of coordination, this theoretical work seems currently to conclude that the gains are likely to be very small in magnitude. Clearly this calls for empirical investigation. Given that this paper finds empirical evidence that many countries do in practice coordinate their monetary policies to some degree, this raises the question of whether the theoretical models perhaps may be missing some element that makes such coordination worthwhile. Future empirical work using the present methodology could help guide continued theoretical research by exploring what factors lead some countries to coordinate more than others. Depending on data limitations, future work should also consider various sub-periods of the sample, to explore conditions under which a particular country is more likely to coordinate.

\section{References}

Batten, Dallas S. and Mack Ott (1985) "The Interrelationship of Monetary Policies Under Floating Exchange Rates," Journal of Money Credit and Banking, 17, 103-110. Benigno, Pierpaolo (2000) "A Simple Approach to International Monetary Policy Co- 
ordination, mimeo: Princeton University.

Biltoft, Karsten and Christian Boersch (1992) "Interest Rate Causality and Asymmetry in the EMS," Open Economies Review 3, 297-306.

Borio, C.E.V. (1997) "Monetary Policy Operating Procedures in Industrial Countries," Bank for International Settlements working paper.

Bryant, Ralph C., Dale W. Henderson, Gerald Holtham, Peter Hooper, and Steven A. Symansky, eds. (1988) Empirical Macroeconomics for Interdependent Economies. Washington, DC: Brookings Institution.

Burdekin, Richard C.K. (1989) "International Transmission of US Macroeconomics Policy and the Inflation Record of Western Europe," Journal of International Money and Finance 8, 401-423.

Burdekin, Richard C.K. and Paul Burkett (1992) "The Impact of U.S. Economic Variables on Bank of Canada Policy: Direct and Indirect Responses," Journal of International Money and Finance, 11, 162-187.

Chung, Jae Wan (1993) "Monetary Interdependence Among G-3 Countries," Applied Economics, 25, 681-688.

Demiralp Selva and Oscar Jorda (2001) "The Pavlovian Response of Term Rates to Fed Announcements," Finance and Economics Discussion Paper 2001-10.

Dominguez, Kathryn M. E. (1997) "Do the G-3 Countries Coordinate Monetary Policy?," in Cohen, Benjamin J. ed.: International Trade and Finance: New Frontiers for Research: Essays in Honor of Peter B. Kenen, New York: Cambridge University Press, 280-315.

Evans, C. L. and Kuttner, K. N. (1998), "Can VARs Describe Monetary Policy?," Federal Reserve Bank of Chicago Working Paper 98-19.

Fischer, Stanley (1988) "Macroeconomic Policy" in: International Economic Cooperation, Martin Feldstein ed., Chicago: University of Chicago Press, 11-43.

Frankel, Jeffrey A., and Katherine Rockett (1988) "International Macroeconomic Policy Coordination When Policy-makers Do Not Agree on the True Model," American Economic Review 78, 318-40.

Fratianni, Michele and Juergen von Hagen (1990a) "German Dominance in the EMS: Evidence from Interest Rates," Journal of International Money and Finance 9, 358-75.

Fratianni, Michele and Juergen von Hagen (1990b) "The European Monetary System: Ten Years After," Carnegie Rochester Conference Series on Public Policy, 32, 173-241.

Furman, Jason and John Leahy (1996) "International Transmission of Monetary Policy: The US and Canada," Harvard University discussion paper, December. 
Garcia-Herrero, Alicia and John Thorton (1996) "Additional Evidence on EMS Interest Rate Linkages," IMF working paper, October.

Hamilton, J. D. (1996) "The Daily Market for Federal Funds," Journal of Political Economy, vol. 104, no. 11, 26-56.

Hamilton J.D. and O. Jorda (2000) "A Model for the Federal Funds Rate Target," NBER working paper 7847.

Karfakis, Costas J. and Demetrios M. Moschos (1990) "Interest Rate Linkages Within the European Monetary System: A Time Series Analysis," Journal of Money, Credit and Banking 22, 388-394.

Katsimbris, George M. and Stephen M. Miller (1993) "Interest Rate Linkages Within the European Monetary System: Further Analysis," Journal of Money Credit and Banking 25, 771-779.

Obstfeld, Maurice and Kenneth Rogoff (2000) "Do We Really Need A New International Monetary Compact?" NBER Working Paper \#7864.

Oudiz, Gilles and Jeffrey Sachs (1984) "Macroeconomic Policy Coordination Among the Industrial Economies," Brookings Papers on Economic Activity 1, 1-64.

Rudebusch, G. D. (1995), "Federal Reserve Interest Rate Targeting, Rational Expectations and the Term Structure," Journal of Monetary Economics, 35, 245-74.

Rudebusch, G. D. (1998), "Do Measures of Monetary Policy in a VAR Make Sense?" International Economic Review 39, 907-31.

Sims, C. A. (1998), "Comment on Glenn Rudebusch's 'Do Measures of Monetary Policy in a VAR Make Sense?" "International Economic Review 39, 933-41.

Taylor, John, ed. (1999) Monetary Policy Rules, Chicago: University of Chicago Press.

von Hagen, Juergen and Michele Fratianni (1990a) "German Dominance in the EMS: The Empirical Evidence," Open Economies Review 1, 67-87.

von Hagen, Juergen and Michele Fratianni (1990b) "German Dominance in the EMS: Evidence from Interest Rates," Journal of International Money and Finance 9, 358-375.

Wrase, J. M. (1998), "Is the Fed being Swept out of (Monetary) Control?" Federal Reserve Bank of Philadelphia Business Review, Nov-Dec, 3-12. 
Table 1 - Summary of the Data Definitions

\begin{tabular}{|c|c|c|c|c|c|}
\hline COUNTRY & Operational Monetary Data & Codes & $\begin{array}{l}\text { Sample } \\
\text { Begins }\end{array}$ & Macro-International Data & Frequency \\
\hline Australia & $\begin{array}{ll}\text { - } & \text { Unofficial cash rate } \\
\text { - } & \text { Target Rate }\end{array}$ & $\begin{array}{l}\text { ONAU } \\
\boldsymbol{P R A} \boldsymbol{U}\end{array}$ & $\begin{array}{l}1 / 1 / 86 \\
1 / 23 / 90\end{array}$ & $\begin{array}{l}\text { GDP, CPI, Nominal Effective } \\
\text { Exchange Rate (NEER) }\end{array}$ & $\begin{array}{l}\text { Quarterly (up to } \\
\text { 7/98), monthly }\end{array}$ \\
\hline Austria & $\begin{array}{ll} & \text { Day-to-day money } \\
- & \text { Short-term operations (GOMEX) } \\
- & \text { Lombard Rate } \\
\end{array}$ & $\begin{array}{l}\text { ONAT } \\
\boldsymbol{P R A T} \\
\text { LRAT }\end{array}$ & $\begin{array}{l}1 / 6 / 89 \\
6 / 5 / 85 \\
1 / 24 / 80\end{array}$ & $\begin{array}{l}\text { Industrial Production (IP), CPI, } \\
\text { NEER }\end{array}$ & Monthly \\
\hline Belgium & $\begin{array}{ll} & \text { Overnight interbank deposits } \\
\text { - } & \text { Central Rate } \\
\end{array}$ & $\begin{array}{l}\mathrm{ONBE} \\
\boldsymbol{P} \boldsymbol{R} \boldsymbol{B} \boldsymbol{E}\end{array}$ & $\begin{array}{l}1 / 2 / 91 \\
1 / 29 / 91 \\
\end{array}$ & IP, CPI, NEER & Monthly \\
\hline Canada & $\begin{array}{ll} & \text { Overnight rate } \\
- & \text { Operating target band } \\
\end{array}$ & $\begin{array}{l}\text { ONCA } \\
\boldsymbol{P R} \boldsymbol{C A}\end{array}$ & $\begin{array}{l}1 / 2 / 80 \\
4 / 15 / 94 \\
\end{array}$ & IP, CPI, NEER & Monthly \\
\hline France & $\begin{array}{ll} & \text { Day-to-day rate } \\
- & \text { Tender rate } \\
\text { - } & \text { 5-10 day repurchase facility } \\
\end{array}$ & $\begin{array}{l}\text { ONFR } \\
\boldsymbol{P R} \boldsymbol{R} \boldsymbol{R} \\
\text { OCFR }\end{array}$ & $\begin{array}{l}1 / 1 / 80 \\
1 / 4 / 82 \\
10 / 12 / 88\end{array}$ & IP, CPI, NEER & Monthly \\
\hline Germany & $\begin{array}{ll}- & \text { Day-to-day rate } \\
- & \text { Repo rate } \\
- & \text { Lombard rate } \\
\end{array}$ & $\begin{array}{l}\text { ONDE } \\
\boldsymbol{P R} \boldsymbol{D E} \\
\text { LRDE }\end{array}$ & $\begin{array}{l}1 / 2 / 80 \\
4 / 1 / 80 \\
1 / 1 / 80\end{array}$ & IP, CPI, NEER & Monthly \\
\hline Italy & $\begin{array}{ll}\text { - } & \text { Overnight interbank deposits } \\
\text { - } & \text { 3-month interbank } \\
\text { - } & \text { Tender rate } \\
\end{array}$ & $\begin{array}{l}\text { ONIT } \\
\text { M3IT } \\
\text { LRIT }\end{array}$ & $\begin{array}{l}10 / 1 / 87 \\
2 / 27 / 90 \\
5 / 13 / 91\end{array}$ & IP, CPI, NEER & Monthly \\
\hline Japan & $\begin{array}{ll} & \text { Overnight call money rate } \\
\text { - } & \text { Discount rate } \\
\end{array}$ & $\begin{array}{l}\text { ONJP } \\
\text { DRJP }\end{array}$ & $\begin{array}{l}7 / 3 / 85 \\
1 / 1 / 85 \\
\end{array}$ & IP (up to 5/98), CPI, NEER & Monthly \\
\hline Netherlands & $\begin{array}{ll}- & \text { Call money } \\
- & \text { Rate on special advances } \\
- & \text { Rate on advances (quota scheme) } \\
\end{array}$ & $\begin{array}{l}\text { ONNL } \\
\text { PRNL } \\
\text { DRNL } \\
\end{array}$ & $\begin{array}{l}1 / 2 / 80 \\
1 / 2 / 80 \\
1 / 2 / 85 \\
\end{array}$ & IP, CPI, NEER & Monthly \\
\hline Spain & $\begin{array}{ll}- & \text { Overnight interbank deposits } \\
- & \text { 10-day repo purchases (marginal rate) }\end{array}$ & $\begin{array}{l}\text { ONES } \\
\text { PRES }\end{array}$ & $\begin{array}{l}1 / 2 / 80 \\
5 / 14 / 90 \\
\end{array}$ & IP, CPI, NEER & Monthly \\
\hline Sweden & $\begin{array}{ll}- & \text { Day-to-day money } \\
- & \text { Repo Rate } \\
\end{array}$ & $\begin{array}{l}\text { ONSE } \\
\boldsymbol{P R S E}\end{array}$ & $\begin{array}{l}11 / 21 / 88 \\
6 / 1 / 94 \\
\end{array}$ & IP, CPI, NEER & Monthly \\
\hline Switzerland & $\begin{array}{ll} & \text { Day-to-day money (tomorrow next) } \\
\text { - } & \text { Flexible Lombard rate }\end{array}$ & $\begin{array}{l}\mathrm{ONCH} \\
\boldsymbol{L} \boldsymbol{R} \boldsymbol{C H}\end{array}$ & $\begin{array}{l}1 / 4 / 80 \\
5 / 26 / 89 \\
\end{array}$ & GDP. CPI, NEER & $\begin{array}{l}\text { Quarterly, } \\
\text { monthly }\end{array}$ \\
\hline$U . K$. & $\begin{array}{ll}\text { - } & \text { Overnight sterling interbank deposits } \\
\text { - } & \text { Band } 1 \text { bank bill purchases } \\
\end{array}$ & $\begin{array}{l}\text { ONGB } \\
\boldsymbol{P R} \boldsymbol{G B}\end{array}$ & $\begin{array}{l}1 / 2 / 80 \\
1 / 2 / 80 \\
\end{array}$ & IP (up to 7/98), CPI, NEER & Monthly \\
\hline$U . S$. & $\begin{array}{ll} & \text { Federal funds rate } \\
\text { - } & \text { Federal funds rate target } \\
\end{array}$ & $\begin{array}{l}\text { ONUS } \\
\text { PRUS }\end{array}$ & $\begin{array}{l}3 / 4 / 84 \\
3 / 4 / 84 \\
\end{array}$ & IP, CPI, NEER & Monthly \\
\hline
\end{tabular}

Note: Target rates in bold and italic. 
Table 2 - Hazard Estimates from a simple Logit model with target dummies for Germany, Japan and the U.S. as dependent variables.

\section{Weekly Frequency}

\begin{tabular}{|c|c|c|c|c|c|c|c|c|c|c|c|c|c|c|}
\hline & Austria & Australia & Belgium & Canada & Switz. & Germany & Spain & France & Italy & Japan & Nether. & Sweden & UK & $\mathbf{U S}$ \\
\hline Japan & 0.09 & 0.00 & 0.16 & 0.00 & 0.87 & 0.27 & 0.09 & 0.08 & 0.10 & 0.03 & 0.23 & 0.34 & 0.17 & 0.11 \\
\hline
\end{tabular}

Note: Baseline measures the probability that in any given week the target will be changed. Germany, Japan, US measure this probability when in addition Germany, Japan and U.S. change their target.

* means significant at the $95 \%$ level.

** means significant at the $90 \%$ level.

\section{Monthly Frequency}

\begin{tabular}{|c|c|c|c|c|c|c|c|c|c|c|c|c|c|c|}
\hline & Austria & Australia & Belgium & Canada & Switz. & Germany & Spain & France & Italy & Japan & Nether. & Sweden & UK & US \\
\hline Germany & $0.56^{*}$ & 0.11 & $0.79^{*}$ & 0.44 & 0.71 & 0.49 & $0.55^{\star *}$ & $0.43^{*}$ & 0.42 & 0.16 & $0.70^{\star}$ & 0.45 & 0.20 & 0.42 \\
\hline Japan & 0.01 & 0.23 & 0.11 & 1.00 & 0.73 & $0.70^{\star *}$ & 0.18 & 0.15 & 0.20 & 0.07 & 0.59 & 0.50 & 0.26 & 0.33 \\
\hline US & 0.01 & $0.34^{*}$ & $0.30^{* *}$ & 0.59 & 0.82 & 0.57 & 0.44 & 0.24 & 0.30 & 0.07 & 0.33 & 0.43 & $0.54^{*}$ & 0.34 \\
\hline
\end{tabular}

Note: Baseline measures the probability that in any given week the target will be changed. Germany, Japan, US measure this probability when in addition Germany, Japan and U.S. change their target.

* means significant at the $95 \%$ level.

** means significant at the $90 \%$ level. 


\section{Table 3 - Monte-Carlo Experiments}

Changing the Frequency of Target Changes - No correlation in the timing, $\beta=0$

\begin{tabular}{ccccc}
\hline $\begin{array}{c}\text { Theoretical } \\
\text { Frequency }\end{array}$ & $\begin{array}{c}\text { Empirical } \\
\text { Frequency A/and B }\end{array}$ & $\begin{array}{c}\text { Directional } \\
\text { Correlation }-\psi\end{array}$ & $\begin{array}{c}\text { B Granger-causes A } \\
\text { p-value }\end{array}$ & $\begin{array}{c}\text { A Granger-causes B } \\
\text { p-value }\end{array}$ \\
\hline 0.4 & $0.403 / 0.400$ & 0.99 & 0.0185 & 0.6570 \\
& & 0.75 & 0.0393 & 0.6700 \\
& 0.50 & 0.1316 & 0.6927 \\
& 0.25 & 0.4045 & 0.7001 \\
& & 0.00 & 0.6140 & 0.6894 \\
\hline 0.3 & $0.304 / 0.301$ & 0.99 & 0.0864 & 0.6264 \\
& & 0.75 & 0.1280 & 0.6446 \\
& 0.50 & 0.2573 & 0.6679 \\
& 0.25 & 0.4982 & 0.6908 \\
0.2 & 0.00 & 0.6322 & 0.6768 \\
\hline & $0.202 / 0.199$ & 0.99 & 0.2658 & 0.6306 \\
& & 0.75 & 0.3302 & 0.6256 \\
& & 0.50 & 0.4498 & 0.6363 \\
& 0.25 & 0.5989 & 0.6428 \\
\hline \hline
\end{tabular}

Note: $\rho^{A}=\rho^{B}=0.5, \gamma^{A}=\gamma^{B}=0.5, \sigma_{A}=\sigma_{B}=0.25$,

Changing the Correlation in the Timing - Directional Correlation $\psi=\mathbf{0 . 7 5}$

\begin{tabular}{cccc}
\hline \hline Timing Correlation - $\beta$ & $\begin{array}{c}\text { B Granger-causes A } \\
\text { p-value }\end{array}$ & $\begin{array}{c}\text { A Granger-causes B } \\
\text { p-value }\end{array}$ & $\begin{array}{c}\text { Empirical Frequency } \\
\text { A }\end{array}$ \\
\hline 0.25 & 0.0392 & 0.6638 & 0.403 \\
0.5 & 0.0410 & 0.6553 & 0.402 \\
0.75 & 0.0408 & 0.6488 & 0.401 \\
0.99 & 0.0427 & 0.6453 & 0.401 \\
\hline \hline
\end{tabular}

Note: $\rho^{A}=\rho^{B}=0.5, \gamma^{A}=\gamma^{B}=0.5, \sigma_{A}=\sigma_{B}=0.25$, Empirical Frequency for $B=0.400$

Changing the Variance of the Errors around the Target $-\beta=0.99, \psi=0.99$

\begin{tabular}{ccc}
\hline \hline$\sigma_{A}=\sigma_{B}=$ & B Granger-causes A: p-value & A Granger-causes B: p-value \\
\hline 1 & 0.4387 & 0.5016 \\
0.5 & 0.1583 & 0.5682 \\
0.25 & 0.0207 & 0.6204 \\
0.1 & 0.0151 & 0.6293 \\
\hline \hline
\end{tabular}

Note: $\rho^{A}=\rho^{B}=0.5, \gamma^{A}=\gamma^{B}=0.5, \sigma_{A}=\sigma_{B}=0.25$, Empirical Frequency for $A=0.400, B=0.400$ 


\section{Table 3 (Contd.)}

Changing the Autocorrelation of the Timing Process $-\beta=0.75, \psi=0.75$

\begin{tabular}{ccccc}
\hline \hline$\rho_{A}=\rho_{B}=$ & $\begin{array}{c}\text { B Granger-causes A } \\
\text { p-value }\end{array}$ & $\begin{array}{c}\text { A Granger-causes B } \\
\text { p-value }\end{array}$ & $\begin{array}{c}\text { Empirical } \\
\text { Frequency A }\end{array}$ & $\begin{array}{c}\text { Empirical } \\
\text { Frequency B }\end{array}$ \\
\hline 0.9 & 0.1227 & 0.5967 & 0.332 & 0.302 \\
0.75 & 0.1304 & 0.6117 & 0.306 & 0.301 \\
0.5 & 0.1231 & 0.6270 & 0.304 & 0.301 \\
0.25 & 0.1225 & 0.6282 & 0.303 & 0.301 \\
0 & 0.1325 & 0.6215 & 0.303 & 0.301 \\
\hline \hline
\end{tabular}

Note: $\gamma^{A}=\gamma^{B}=0.5, \sigma_{A}=\sigma_{B}=0.25$.

Changing the Autocorrelation of the Directional Process $-\beta=\mathbf{0 . 7 5}, \psi=0.75$

\begin{tabular}{ccc}
\hline \hline$\gamma^{A}=\gamma^{B}=$ & B Granger-causes A: p-value & A Granger-causes B: p-value \\
\hline 0.9 & 0.1084 & 0.4319 \\
0.75 & 0.1096 & 0.5320 \\
0.5 & 0.1231 & 0.6270 \\
0.25 & 0.1941 & 0.6500 \\
0 & 0.2374 & 0.6609 \\
\hline \hline
\end{tabular}

Note: $\rho^{A}=\rho^{B}=0.5, \sigma_{A}=\sigma_{B}=0.25$, Empirical Frequency for $A=0.303, B=0.301$

\section{Equations of the Monte Carlo Simulation}

$$
\begin{aligned}
& r_{t}^{i}=\bar{r}_{t}^{i}+\varepsilon_{i t} \quad \varepsilon_{i t} \sim N\left(0, \sigma_{i}^{2}\right) \quad i=A, B \\
& \bar{r}_{t}^{i}=x_{t}^{i} \bar{r}_{t-1}^{i}+\left(1-x_{t}^{i}\right)\left(\bar{r}_{t-1}^{i}+\Delta \bar{r}_{t}^{i}\right) \\
& P\left(\Delta \bar{r}_{t}^{i}=k_{j} \mid x_{t}^{i}=1, \Omega_{t-1}\right)=P\left(c_{j-1}<\Delta r_{t}^{i *}<c_{j} \mid x_{t}^{i}=1, \Omega_{t-1}\right) \quad j=1,2, \ldots, m \\
& \text { with } m=5, k_{1}=-0.50 ; k_{2}=-0.25 ; k_{3}=0.25 ; k_{4}=0.50 ; \text { and } c_{1}=-\infty ; c_{2}=-.75 ; c_{3}=0 ; c_{4} \\
& =0.75 ; c_{5}=\infty
\end{aligned}
$$

\section{Timing Model}

$h_{t}^{i}=\frac{1}{1+e^{\lambda_{t}^{i}}}$

$\left\{\begin{array}{c}\lambda_{t}^{A}=\omega_{A}+\rho_{A} \lambda_{t-1}^{A}+\beta \lambda_{t-1}^{B}+e_{t}^{A} \\ \lambda_{t}^{B}=\omega_{B}+\rho_{B} \lambda_{t-1}^{B}+\end{array} \quad e_{t}^{B} \quad e_{t}^{i} \sim N(0,0.1)\right.$

$x_{t}^{i}=1$ if $h_{t}^{i}>u_{t}^{i}, 0$ otherwise, where $u_{t}^{i}$ is a uniform $[0,1]$

\section{Directional Model}

$$
\left\{\begin{array}{c}
\Delta r_{t}^{A^{*}}=\gamma_{A} \Delta r_{t-1}^{A^{*}}+\varphi \Delta r_{t-1}^{B^{*}}+v_{t}^{A} \\
\Delta r_{t}^{B^{*}} \quad=\gamma_{B} \Delta r_{t-1}^{B^{*}}+v_{t}^{B}
\end{array} \quad v_{t}^{i} \sim N(0,1)\right.
$$




\section{Table 4 - Classification of Target Changes}

\begin{tabular}{ccccc}
\hline \hline Country & $\begin{array}{c}\boldsymbol{k}_{1}=\text { strong } \\
\text { decrease }\end{array}$ & $\boldsymbol{k}_{2}=$ decrease & $\boldsymbol{k}_{3}=$ increase & $\begin{array}{c}\boldsymbol{k}_{4}=\text { strong } \\
\text { increase }\end{array}$ \\
\hline Australia & $\Delta \bar{r}_{t}<-0.75$ & $-0.75 \leq \Delta \bar{r}_{t} \leq 0$ & $0<\Delta \bar{r}_{t} \leq 0.75$ & $\Delta \bar{r}_{t}>0.75$ \\
Austria & $\Delta \bar{r}_{t}<-0.5$ & $-0.5 \leq \Delta \bar{r}_{t} \leq 0$ & $0<\Delta \bar{r}_{t} \leq 0.5$ & $\Delta \bar{r}_{t}>0.5$ \\
Belgium & $\Delta \bar{r}_{t}<-0.5$ & $-0.5 \leq \Delta \bar{r}_{t} \leq 0$ & $0<\Delta \bar{r}_{t} \leq 0.5$ & $\Delta \bar{r}_{t}>0.5$ \\
Canada & $\Delta \bar{r}_{t} \leq-0.5$ & $-0.5<\Delta \bar{r}_{t} \leq 0$ & $0<\Delta \bar{r}_{t}<0.5$ & $\Delta \bar{r}_{t} \geq 0.5$ \\
France & $\Delta \bar{r}_{t} \leq-0.4$ & $-0.4<\Delta \bar{r}_{t} \leq 0$ & $0<\Delta \bar{r}_{t} \leq 0.4$ & $\Delta \bar{r}_{t}>0.4$ \\
Germany & $\Delta \bar{r}_{t} \leq-0.4$ & $-0.4<\Delta \bar{r}_{t} \leq 0$ & $0<\Delta \bar{r}_{t} \leq 0.4$ & $\Delta \bar{r}_{t}>0.4$ \\
Italy & $\Delta \bar{r}_{t}<-0.5$ & $-0.5 \leq \Delta \bar{r}_{t} \leq 0$ & $0<\Delta \bar{r}_{t} \leq 0.5$ & $\Delta \bar{r}_{t}>0.5$ \\
Japan & $\Delta \bar{r}_{t}<-0.5$ & $-0.5 \leq \Delta \bar{r}_{t} \leq 0$ & $0<\Delta \bar{r}_{t} \leq 0.5$ & $\Delta \bar{r}_{t}>0.5$ \\
Netherlands & $\Delta \bar{r}_{t} \leq-0.4$ & $-0.4<\Delta \bar{r}_{t} \leq 0$ & $0<\Delta \bar{r}_{t} \leq 0.4$ & $\Delta \bar{r}_{t}>0.4$ \\
Spain & $\Delta \bar{r}_{t}<-0.5$ & $-0.5 \leq \Delta \bar{r}_{t} \leq 0$ & $0<\Delta \bar{r}_{t} \leq 0.5$ & $\Delta \bar{r}_{t}>0.5$ \\
Sweden & $\Delta \bar{r}_{t} \leq-0.3$ & $-0.3<\Delta \bar{r}_{t} \leq 0$ & $0<\Delta \bar{r}_{t}<0.3$ & $\Delta \bar{r}_{t} \geq 0.3$ \\
U.K. & $\Delta \bar{r}_{t}<-0.5$ & $-0.5 \leq \Delta \bar{r}_{t} \leq 0$ & $0<\Delta \bar{r}_{t} \leq 0.5$ & $\Delta \bar{r}_{t}>0.5$ \\
U.S. & $\Delta \bar{r}_{t} \leq-0.5$ & $-0.5<\Delta \bar{r}_{t} \leq 0$ & $0<\Delta \bar{r}_{t}<0.5$ & $\Delta \bar{r}_{t} \geq 0.5$ \\
\hline \hline
\end{tabular}


Table 5: ACH Estimation Results

\begin{tabular}{|c|c|c|c|c|c|c|c|}
\hline & Australia & Austria & Belgium & Canada & France & Germany & Italy \\
\hline constant & $\begin{array}{c}0.557 \\
(0.538)\end{array}$ & $\begin{array}{l}-0.125 \\
(0.621)\end{array}$ & $\begin{array}{l}-2.577 \\
(1.842)\end{array}$ & $\begin{array}{l}4.130^{* * *} \\
(3.148)\end{array}$ & $\begin{array}{l}-0.022 \\
(0.421)\end{array}$ & $\begin{array}{l}5.560 * \\
(2.175)\end{array}$ & $\begin{array}{c}0.985 \\
(1.268)\end{array}$ \\
\hline duration & $\begin{array}{c}0.336 \\
(0.402)\end{array}$ & $\begin{array}{l}-0.321 \\
(0.293)\end{array}$ & -- & $\begin{array}{c}0.093 \\
(0.626)\end{array}$ & $\begin{array}{l}-0.178 \\
(0.196)\end{array}$ & $\begin{array}{l}-0.245 \\
(0.264)\end{array}$ & -- \\
\hline r & $\begin{array}{l}0.869 * \\
(0.094)\end{array}$ & $\begin{array}{l}0.823 * \\
(0.126)\end{array}$ & -- & $\begin{array}{l}-0.725^{*} \\
(0.199)\end{array}$ & $\begin{array}{l}0.725^{*} \\
(0.151)\end{array}$ & $\begin{array}{l}-0.217 \\
(0.503)\end{array}$ & -- \\
\hline output (positive) & $\begin{array}{l}-0.102 \\
(0.537)\end{array}$ & $\begin{array}{c}0.1441 * * \\
(0.104)\end{array}$ & $\begin{array}{c}0.012 \\
(0.070)\end{array}$ & $\begin{array}{c}0.282 \\
(0.840)\end{array}$ & $\begin{array}{c}0.1523 * * \\
(0.112)\end{array}$ & $\begin{array}{l}-0.023 \\
(0.130)\end{array}$ & $\begin{array}{c}0.416 * * \\
(0.300)\end{array}$ \\
\hline output (negative) & $\begin{array}{c}0.009 \\
(0.457)\end{array}$ & $\begin{array}{c}0.020 \\
(0.054)\end{array}$ & $\begin{array}{l}-0.004 \\
(0.039)\end{array}$ & $\begin{array}{l}-0.513 \\
(0.571)\end{array}$ & $\begin{array}{c}0.104 \\
(0.119)\end{array}$ & $\begin{array}{l}0.244 * \\
(0.176)\end{array}$ & $\begin{array}{c}0.015 \\
(0.141)\end{array}$ \\
\hline CPI (positive) & $\begin{array}{c}0.268 \\
(0.384)\end{array}$ & -- & -- & -- & -- & $\begin{array}{l}-1.897 * \\
(0.980)\end{array}$ & $\begin{array}{c}1.194 \\
(1.120)\end{array}$ \\
\hline CPI (negative) & $\begin{array}{l}1.206 * * \\
(0.880)\end{array}$ & $\begin{array}{c}0.238 \\
(0.418)\end{array}$ & $\begin{array}{c}0.514 \\
(1.156)\end{array}$ & $\begin{array}{c}0.922 \\
(2.689)\end{array}$ & $\begin{array}{l}-0.365 \\
(0.509)\end{array}$ & $\begin{array}{l}-3.694 * \\
(1.397)\end{array}$ & $\begin{array}{c}1.495 \\
(1.443)\end{array}$ \\
\hline $\begin{array}{l}\text { exchange rate } \\
\text { (positive) }\end{array}$ & $\begin{array}{l}0.345^{*} \\
(0.150)\end{array}$ & $\begin{array}{l}-0.323 * \\
(0.192)\end{array}$ & $\begin{array}{l}-0.150 \\
(0.447)\end{array}$ & $\begin{array}{c}0.089 \\
(0.957)\end{array}$ & $\begin{array}{c}0.220 * * \\
(0.152)\end{array}$ & $\begin{array}{l}-0.727 * \\
(0.378)\end{array}$ & $\begin{array}{l}-0.031 \\
(0.217)\end{array}$ \\
\hline $\begin{array}{l}\text { exchange rate } \\
\text { (negative) }\end{array}$ & $\begin{array}{c}-0.361^{* *} \\
(0.254) \\
\end{array}$ & $\begin{array}{l}-0.167 \\
(0.605) \\
\end{array}$ & $\begin{array}{c}0.649 \\
(0.671) \\
\end{array}$ & $\begin{array}{c}0.741 \\
(0.681) \\
\end{array}$ & $\begin{array}{c}-0.4564 * * \\
(0.320) \\
\end{array}$ & $\begin{array}{l}-0.204 \\
(0.350) \\
\end{array}$ & $\begin{array}{c}0.174 * * \\
(0.128) \\
\end{array}$ \\
\hline German policy & $\begin{array}{c}2.481 \\
(4.097)\end{array}$ & $\begin{array}{c}0.670 \\
(1.017)\end{array}$ & $\begin{array}{c}5.229 \\
(3.216)\end{array}$ & $\begin{array}{l}-1.479 \\
(4.971)\end{array}$ & $\begin{array}{c}1.533 \\
(1.524)\end{array}$ & & $\begin{array}{l}-2.016 \\
(2.952)\end{array}$ \\
\hline Japanese policy & $\begin{array}{c}-5.836^{* *} \\
(4.414)\end{array}$ & $\begin{array}{l}-0.868 \\
(1.395)\end{array}$ & $\begin{array}{c}4.160 \\
(3.098)\end{array}$ & $\begin{array}{l}-8.330 \\
(9.051)\end{array}$ & $\begin{array}{c}-0.062 \\
(1.686)\end{array}$ & $\begin{array}{c}0.323 \\
(2.412)\end{array}$ & $\begin{array}{l}-2.286 \\
(3.549)\end{array}$ \\
\hline U.S. policy & $\begin{array}{c}-0.645 \\
(0.968) \\
\end{array}$ & $\begin{array}{c}0.477 \\
(0.918) \\
\end{array}$ & $\begin{array}{l}-2.795 \\
(2.409) \\
\end{array}$ & $\begin{array}{c}-7.114 \\
(5.692) \\
\end{array}$ & $\begin{array}{c}-0.416 \\
(1.318) \\
\end{array}$ & $\begin{array}{l}-4.529 * \\
(2.184) \\
\end{array}$ & $\begin{array}{c}-3.147^{* *} * \\
(0.234) \\
\end{array}$ \\
\hline Date range: & $1 / 90-7 / 98$ & $6 / 85-7 / 98$ & $1 / 91-7 / 98$ & 4/94-7/98 & 9/88-7/98 & 9/91-7/98 & $1 / 91-7 / 98$ \\
\hline
\end{tabular}

Standard errors in parentheses. * Indicates significant at the $95 \%$ level; ** indicates significant at the $90 \%$ level.

-- indicates that this variable was excluded because the estimation would not converge when it was included. 
Table 5 continued

\begin{tabular}{|c|c|c|c|c|c|c|c|}
\hline & Japan & Nethlds & Spain & Sweden & Switz. & U.K. & U.S. \\
\hline constant & $\begin{array}{l}6.061 * \\
(2.250)\end{array}$ & $\begin{array}{l}-1.585 \\
(1.281)\end{array}$ & $\begin{array}{l}-1.643 \\
(1.740)\end{array}$ & $\begin{array}{c}-15.092 * \\
(5.870)\end{array}$ & $\begin{array}{l}-1.802 \\
(1.543)\end{array}$ & $\begin{array}{c}4.070 \\
(1.800)\end{array}$ & $\begin{array}{c}0.904 \\
(0.711)\end{array}$ \\
\hline duration & $\begin{array}{l}2.704 * \\
(1.195)\end{array}$ & -- & $\begin{array}{c}0.177 \\
(1.605)\end{array}$ & -- & $\begin{array}{l}-0.550 \\
(0.874)\end{array}$ & $\begin{array}{l}-0.140 \\
(0.300)\end{array}$ & $\begin{array}{l}-0.169 \\
(0.157)\end{array}$ \\
\hline $\mathrm{r}$ & $\begin{array}{c}-0.8814^{*} \\
(0.051) \\
\end{array}$ & -- & $\begin{array}{c}0.275 \\
(0.336) \\
\end{array}$ & -- & $\begin{array}{r}0.214 \\
(0.273) \\
\end{array}$ & $\begin{array}{c}-0.249 * * \\
(0.180) \\
\end{array}$ & $\begin{array}{r}0.792 \\
(0.123) \\
\end{array}$ \\
\hline output (positive) & $\begin{array}{c}0.002 \\
(0.147)\end{array}$ & $\begin{array}{c}0.016 \\
(0.023)\end{array}$ & $\begin{array}{c}0.178 \\
(0.163)\end{array}$ & $\begin{array}{l}1.887 * \\
(0.924)\end{array}$ & $\begin{array}{c}0.199 * * \\
(0.138)\end{array}$ & $\begin{array}{l}-0.497 * \\
(0.282)\end{array}$ & $\begin{array}{c}-0.120 * * \\
(0.080)\end{array}$ \\
\hline output (negative) & $\begin{array}{c}0.094 \\
(0.222)\end{array}$ & $\begin{array}{l}-0.002 \\
(0.028)\end{array}$ & $\begin{array}{c}0.165 \\
(0.148)\end{array}$ & $\begin{array}{l}-0.211 \\
(0.944)\end{array}$ & $\begin{array}{l}-0.067 \\
(0.148)\end{array}$ & $\begin{array}{c}0.026 \\
(0.228)\end{array}$ & $\begin{array}{l}-0.010 \\
(0.034)\end{array}$ \\
\hline CPI (positive) & -- & -- & $\begin{array}{c}0.667 \\
(0.765)\end{array}$ & -- & $\begin{array}{c}-69.892 \\
(771.942)\end{array}$ & $\begin{array}{l}3.079 * \\
(1.481)\end{array}$ & $\begin{array}{l}-0.184 \\
(0.226)\end{array}$ \\
\hline CPI (negative) & $\begin{array}{l}-0.539 \\
(1.236)\end{array}$ & $\begin{array}{l}-0.394 \\
(0.627)\end{array}$ & $\begin{array}{l}1.786 * * \\
(1.147)\end{array}$ & $\begin{array}{c}-4.440 * * \\
(2.385)\end{array}$ & $\begin{array}{c}0.613 \\
(1.010)\end{array}$ & $\begin{array}{l}2.661 * \\
(1.576)\end{array}$ & $\begin{array}{l}-0.153 \\
(0.399)\end{array}$ \\
\hline $\begin{array}{l}\text { exchange rate } \\
\text { (positive) }\end{array}$ & $\begin{array}{c}0.135 \\
(0.208)\end{array}$ & $\begin{array}{c}0.378 \\
(0.257)\end{array}$ & $\begin{array}{l}-0.477 \\
(0.583)\end{array}$ & $\begin{array}{c}1.443 \\
(0.915)\end{array}$ & $\begin{array}{l}0.771 * \\
(0.394)\end{array}$ & $\begin{array}{l}-1.020 * \\
(0.399)\end{array}$ & $\begin{array}{l}0.350 * \\
(0.134)\end{array}$ \\
\hline $\begin{array}{l}\text { exchange rate } \\
\text { (negative) }\end{array}$ & $\begin{array}{c}0.236 \\
(0.210) \\
\end{array}$ & $\begin{array}{l}-0.595 \\
(0.432) \\
\end{array}$ & $\begin{array}{c}0.019 \\
(0.170) \\
\end{array}$ & $\begin{array}{l}-1.605 \\
(1.131) \\
\end{array}$ & $\begin{array}{l}-0.309 \\
(0.296) \\
\end{array}$ & $\begin{array}{l}0.526 * \\
(0.314) \\
\end{array}$ & $\begin{array}{l}-0.020 \\
(0.056) \\
\end{array}$ \\
\hline German policy & $\begin{array}{l}-3.978 \\
(3.216)\end{array}$ & $\begin{array}{l}4.359 * \\
(1.746)\end{array}$ & $\begin{array}{l}-1.335 \\
(2.242)\end{array}$ & $\begin{array}{c}16.849 * * \\
(10.108)\end{array}$ & $\begin{array}{c}1.118 \\
(2.797)\end{array}$ & $\begin{array}{c}1.247 \\
(2.107)\end{array}$ & $\begin{array}{c}-1.014 \\
(0.837)\end{array}$ \\
\hline Japanese policy & & $\begin{array}{c}1.313 \\
(2.091)\end{array}$ & $\begin{array}{c}0.573 \\
(3.262)\end{array}$ & $\begin{array}{l}-13.544 \\
(11.114)\end{array}$ & $\begin{array}{l}-4.465 \\
(4.453)\end{array}$ & $\begin{array}{c}-4.997 * * \\
(3.114)\end{array}$ & $\begin{array}{c}-0.627 \\
(0.729)\end{array}$ \\
\hline U.S. policy & $\begin{array}{c}-6.4363 * \\
(4.528)\end{array}$ & $\begin{array}{l}-2.061 \\
(1.418)\end{array}$ & $\begin{array}{c}0.382 \\
(1.892)\end{array}$ & $\begin{array}{l}40.668 * \\
(16.554)\end{array}$ & $\begin{array}{l}-1.116 \\
(1.884)\end{array}$ & $\begin{array}{l}-1.534 \\
(2.099)\end{array}$ & \\
\hline Date range: & 9/86-7/98 & $6 / 86-7 / 98$ & $11 / 90-7 / 98$ & $10 / 94-7 / 98$ & 06/89-7/98 & 9/91-7/98 & $1 / 88-7 / 98$ \\
\hline
\end{tabular}

Standard errors in parentheses. * Indicates significant at the 95\% level; ** indicates significant at the $90 \%$ level.

-- indicates that this variable was excluded because the estimation would not converge when it was included. 
Table 6: ACH Estimation Results with Agreement Indicator

\begin{tabular}{|c|c|c|c|c|c|}
\hline & France & Germany & Japan & U.K. & U.S. \\
\hline constant & $\begin{array}{c}24.718 * * \\
(15.494)\end{array}$ & $\begin{array}{c}1.047 \\
(2.887)\end{array}$ & $\begin{array}{l}11.297 * \\
(3.390)\end{array}$ & $\begin{array}{l}-3.567 \\
(3.341)\end{array}$ & $\begin{array}{c}1.138 \\
(2.278)\end{array}$ \\
\hline duration & $\begin{array}{c}0.864 * * \\
(0.539)\end{array}$ & $\begin{array}{l}-0.157 \\
(0.335)\end{array}$ & $\begin{array}{c}0.596 \\
(1.107)\end{array}$ & $\begin{array}{c}-1.197 * * \\
(0.794)\end{array}$ & $\begin{array}{l}-0.304 \\
(0.305)\end{array}$ \\
\hline$\rho$ & $\begin{array}{c}0.174 \\
(0.185) \\
\end{array}$ & $\begin{array}{l}-0.107 \\
(0.270) \\
\end{array}$ & $\begin{array}{c}-0.850 * \\
(0.103) \\
\end{array}$ & $\begin{array}{l}0.482 * \\
(0.186) \\
\end{array}$ & $\begin{array}{l}0.990 * \\
(0.384)\end{array}$ \\
\hline output (positive) & $\begin{array}{c}0.917 \\
(0.745)\end{array}$ & $\begin{array}{l}-0.106 \\
(0.159)\end{array}$ & $\begin{array}{c}-0.138 \\
(0.200)\end{array}$ & $\begin{array}{l}-0.085 \\
(0.319)\end{array}$ & $\begin{array}{c}0.053 \\
(0.187)\end{array}$ \\
\hline output (negative) & $\begin{array}{c}0.293 \\
(0.715)\end{array}$ & $\begin{array}{c}0.313 \\
(0.318)\end{array}$ & $\begin{array}{c}0.181 \\
(0.266)\end{array}$ & $\begin{array}{l}-0.016 \\
(0.232)\end{array}$ & $\begin{array}{l}-0.059 \\
(0.092)\end{array}$ \\
\hline CPI (positive) & -- & $\begin{array}{c}-1.223 * * \\
(0.873)\end{array}$ & -- & $\begin{array}{c}2.037 \\
(2.417)\end{array}$ & $\begin{array}{l}-0.263 \\
(0.571)\end{array}$ \\
\hline CPI (negative) & $\begin{array}{l}-8.070 * \\
(3.773)\end{array}$ & $\begin{array}{c}-2.235^{* *} \\
(1.413)\end{array}$ & $\begin{array}{c}0.724 \\
(1.809)\end{array}$ & $\begin{array}{c}2.851 \\
(2.888)\end{array}$ & $\begin{array}{l}-0.350 \\
(0.867)\end{array}$ \\
\hline $\begin{array}{l}\text { exchange rate } \\
\text { (positive) }\end{array}$ & $\begin{array}{l}-2.399 * \\
(0.852)\end{array}$ & $\begin{array}{l}-0.492 \\
(0.500)\end{array}$ & $\begin{array}{c}-0.207 \\
(0.215)\end{array}$ & $\begin{array}{l}-0.625 \\
(0.669)\end{array}$ & $\begin{array}{c}0.156 \\
(0.351)\end{array}$ \\
\hline $\begin{array}{l}\text { exchange rate } \\
\text { (negative) }\end{array}$ & $\begin{array}{l}7.410 * \\
(2.917) \\
\end{array}$ & $\begin{array}{l}6.285^{*} \\
(2.836) \\
\end{array}$ & $\begin{array}{l}0.538 * \\
(0.260) \\
\end{array}$ & $\begin{array}{c}0.683 * * \\
(0.454)\end{array}$ & $\begin{array}{l}-0.005 \\
(0.153) \\
\end{array}$ \\
\hline German policy & $\begin{array}{l}-13.328 \\
(11.780)\end{array}$ & & $\begin{array}{c}-5.490 * * \\
(3.577)\end{array}$ & $\begin{array}{l}6.422 * \\
(3.667)\end{array}$ & $\begin{array}{c}0.322 \\
(2.318)\end{array}$ \\
\hline Japanese policy & $\begin{array}{c}-16.111 * \\
(8.837)\end{array}$ & $\begin{array}{l}-0.542 \\
(4.907)\end{array}$ & & $\begin{array}{l}-0.144 \\
(3.638)\end{array}$ & $\begin{array}{l}-1.229 \\
(2.420)\end{array}$ \\
\hline U.S. policy & $\begin{array}{c}2.374 \\
(8.487)\end{array}$ & $\begin{array}{c}6.149 * * \\
(3.913)\end{array}$ & $\begin{array}{c}-14.977 * \\
(5.662)\end{array}$ & $\begin{array}{c}1.092 \\
(3.296)\end{array}$ & \\
\hline Agreement Indicator & $\begin{array}{c}1.418 * * \\
(1.051)\end{array}$ & $\begin{array}{c}0.148 \\
(0.603)\end{array}$ & $\begin{array}{c}0.385 \\
(0.422)\end{array}$ & $\begin{array}{c}-0.677 \\
(0.779)\end{array}$ & $\begin{array}{c}-0.656 \\
(0.798)\end{array}$ \\
\hline Date range: & $9 / 88-12 / 93$ & $9 / 91-12 / 93$ & 9/86-12/93 & $9 / 91-12 / 93$ & $1 / 88-12 / 93$ \\
\hline
\end{tabular}


Table 7: Ordered Probit Results

\begin{tabular}{|c|c|c|c|c|c|c|c|}
\hline & Australia & Austria & Belgium & Canada & France & Germany & Italy \\
\hline output & $\begin{array}{c}0.182 \\
(0.516)\end{array}$ & $\begin{array}{l}-0.011 \\
(0.087)\end{array}$ & $\begin{array}{l}-0.033 \\
(0.080)\end{array}$ & $\begin{array}{c}0.178 \\
(0.443)\end{array}$ & $\begin{array}{l}0.348 * \\
(0.149)\end{array}$ & $\begin{array}{l}0.151 * \\
(0.045)\end{array}$ & $\begin{array}{c}0.038 \\
(0.179)\end{array}$ \\
\hline CPI & $\begin{array}{c}-1.034 * * \\
(0.533)\end{array}$ & $\begin{array}{l}-0.806 \\
(1.019)\end{array}$ & $\begin{array}{c}0.099 \\
(0.854)\end{array}$ & $\begin{array}{c}-0.088 \\
(1.407)\end{array}$ & $\begin{array}{c}1.646 \\
(1.165)\end{array}$ & $\begin{array}{c}-0.501 * \\
(0.238)\end{array}$ & $\begin{array}{c}0.302 \\
(0.644)\end{array}$ \\
\hline exchange rate & $\begin{array}{c}0.156 \\
(0.128)\end{array}$ & $\begin{array}{l}-0.400 \\
(0.379)\end{array}$ & $\begin{array}{l}-0.163 \\
(0.158)\end{array}$ & $\begin{array}{c}-0.685^{*} \\
(0.411)\end{array}$ & $\begin{array}{l}-0.623 * \\
(0.255)\end{array}$ & $\begin{array}{c}-0.236 * \\
(0.106)\end{array}$ & $\begin{array}{c}-0.016 \\
(0.090)\end{array}$ \\
\hline German policy & -- & $\begin{array}{l}1.369 * \\
(0.448)\end{array}$ & $\begin{array}{l}0.787 * \\
(0.324)\end{array}$ & $\begin{array}{c}0.193 \\
(0.525)\end{array}$ & $\begin{array}{c}0.897 * * \\
(0.499)\end{array}$ & & $\begin{array}{c}1.384 * \\
(0.556)\end{array}$ \\
\hline Japanese policy & -- & -- & $\begin{array}{c}0.213 \\
(0.259)\end{array}$ & -- & $\begin{array}{c}0.175 \\
(0.316)\end{array}$ & $\begin{array}{l}0.403 * \\
(0.152)\end{array}$ & $\begin{array}{c}-1.780 * \\
(0.526)\end{array}$ \\
\hline U.S. policy & -- & $\begin{array}{c}0.134 \\
(0.358)\end{array}$ & $\begin{array}{c}0.034 \\
(0.248)\end{array}$ & $\begin{array}{c}-0.070 \\
(0.365)\end{array}$ & $\begin{array}{c}0.352 \\
(0.387)\end{array}$ & $\begin{array}{l}0.345 * \\
(0.158)\end{array}$ & $\begin{array}{c}0.892 * \\
(0.363)\end{array}$ \\
\hline Date range: & $1 / 90-7 / 98$ & $6 / 85-7 / 98$ & $1 / 91-7 / 98$ & $4 / 94-7 / 98$ & $9 / 88-7 / 98$ & 9/91-7/98 & $1 / 91-7 / 98$ \\
\hline & Japan & Nethlds & Spain & Sweden & Switz. & U.K. & U.S. \\
\hline output (positive) & $\begin{array}{c}0.234 \\
(0.154)\end{array}$ & $\begin{array}{l}0.025^{*} \\
(0.010)\end{array}$ & $\begin{array}{c}0.026 \\
(0.066)\end{array}$ & -- & $\begin{array}{c}0.007 \\
(0.063)\end{array}$ & $\begin{array}{l}0.358 * \\
(0.097)\end{array}$ & $\begin{array}{l}0.139 * \\
(0.050)\end{array}$ \\
\hline CPI (positive) & $\begin{array}{c}-1.077 \\
(1.465)\end{array}$ & $\begin{array}{c}-1.003 * \\
(0.461)\end{array}$ & $\begin{array}{c}0.207 \\
(0.326)\end{array}$ & $\begin{array}{l}2.248 * \\
(0.911)\end{array}$ & $\begin{array}{c}-0.002 \\
(0.024)\end{array}$ & $\begin{array}{l}-0.150 \\
(0.279)\end{array}$ & $\begin{array}{c}-0.532 * * \\
(0.321)\end{array}$ \\
\hline exchange rate & $\begin{array}{l}-0.301 * \\
(0.110)\end{array}$ & $\begin{array}{l}-.337^{*} \\
(0.126)\end{array}$ & $\begin{array}{c}0.126 \\
(0.121)\end{array}$ & $\begin{array}{c}-0.726^{*} \\
(0.235)\end{array}$ & $\begin{array}{c}-0.049 \\
(0.034)\end{array}$ & $\begin{array}{c}0.013 \\
(0.051)\end{array}$ & $\begin{array}{c}0.097 * * \\
(0.052)\end{array}$ \\
\hline German policy & $\begin{array}{c}-0.399 \\
(0.634)\end{array}$ & $\begin{array}{l}0.451 * \\
(0.183)\end{array}$ & $\begin{array}{l}0.896 * \\
(0.347)\end{array}$ & -- & $\begin{array}{l}-0.100 \\
(0.319)\end{array}$ & $\begin{array}{l}0.574 * \\
(0.234)\end{array}$ & $\begin{array}{c}-0.198 \\
(0.183)\end{array}$ \\
\hline Japanese policy & & $\begin{array}{l}0.393 * \\
(0.158)\end{array}$ & $\begin{array}{c}-0.264 \\
(0.260)\end{array}$ & -- & $\begin{array}{c}0.111 \\
(0.121)\end{array}$ & $\begin{array}{l}-0.396 \\
(0.242)\end{array}$ & $\begin{array}{c}-0.523 * \\
(0.019)\end{array}$ \\
\hline U.S. policy & $\begin{array}{c}0.759 \\
(0.480) \\
\end{array}$ & $\begin{array}{c}0.178 \\
(0.160) \\
\end{array}$ & $\begin{array}{c}0.433 \\
(0.269) \\
\end{array}$ & -- & $\begin{array}{c}0.088 \\
(0.264) \\
\end{array}$ & $\begin{array}{c}0.205 \\
(0.220) \\
\end{array}$ & \\
\hline Date range: & 9/86-7/98 & 6/86-7/98 & $11 / 90-7 / 98$ & 10/94-7/98 & 06/89-7/98 & 9/91-7/98 & $1 / 88-7 / 98$ \\
\hline
\end{tabular}

Standard errors in parentheses. * Indicates significant at the $95 \%$ level; ** indicates significant at the $90 \%$ level.

-- indicates that this variable was excluded because the estimation would not converge when it was included. 
Figure 1 - Targets and Overnight Rates
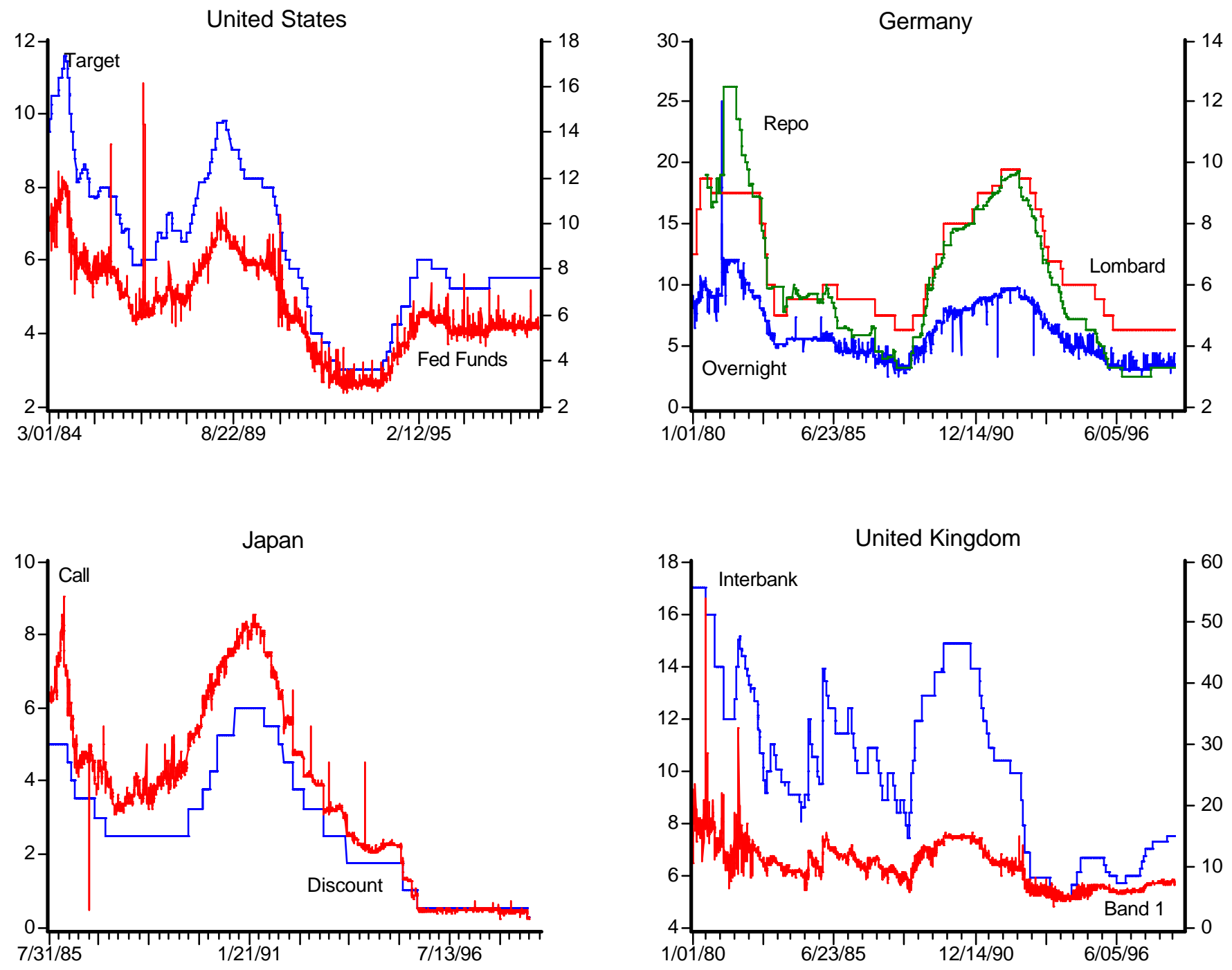

Note: Whenever target and overnight data are indistinguishable, we use dual scales.

This explains the seemingly disimilar pattern in some of the plots. 
Figure 1 - Targets and Overnight Rates (Contd.)
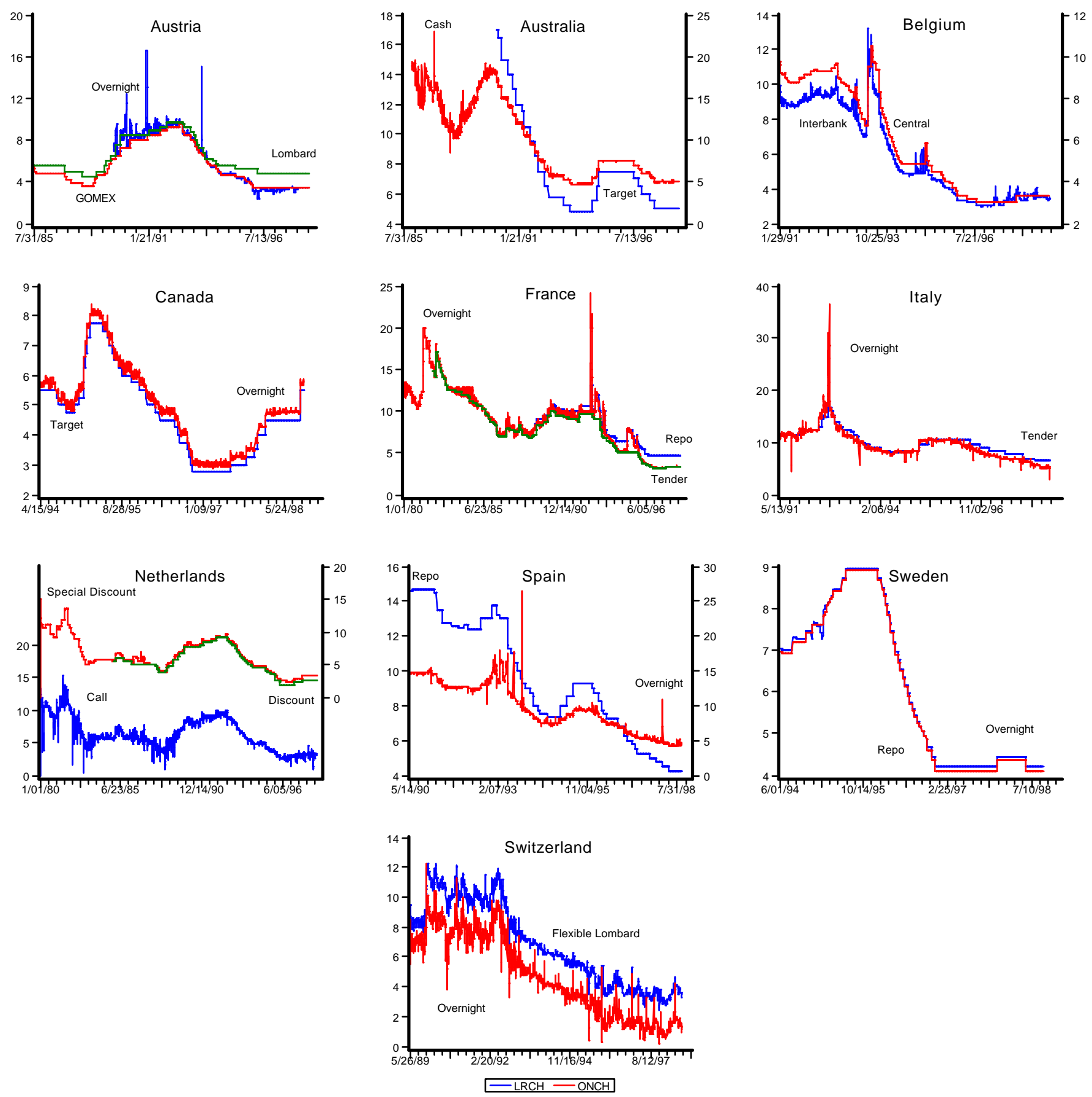


\section{Figure 2 - Example of Monte Carlo Generated Interest Rate Series \\ p-value B Granger-causes A $=0.1231$}

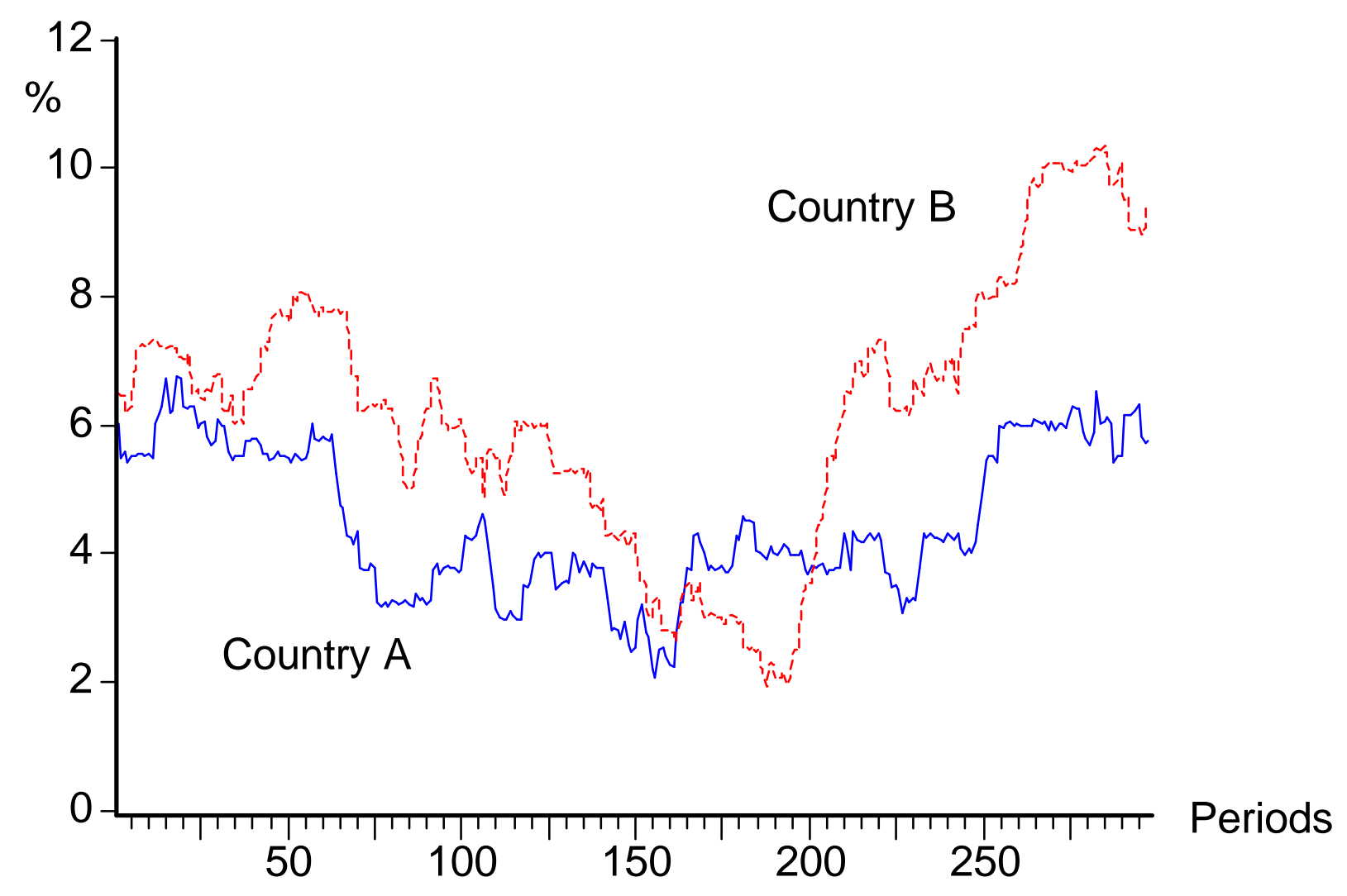

Timing Model Parameters

Directional Model Parameters
$\rho_{\mathrm{A}}=\rho_{\mathrm{B}}=0.5$
$\gamma_{A}=\gamma_{B}=0.5$
$\beta=0.75$
$\varphi=0.75$

Frequency $=0.3$ 